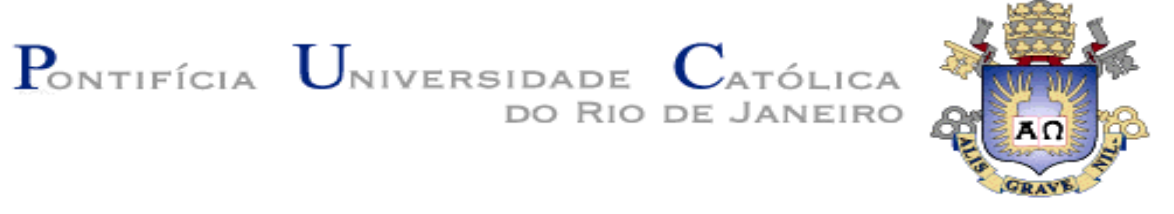

Maria Clara Veloso de Oliveira

\title{
AVALIAÇÃO NEUROPSICOLÓGICA DAS FUNÇÕES EXECUTIVAS DE PRÉ-ESCOLARES
}

Dissertação de Mestrado

Dissertação apresentada ao programa de pós-graduação em Psicologia (Psicologia Clínica) da PUC-Rio como requisito parcial para obtenção do grau de mestre em Psicologia Clínica.

Orientadora: Profa. Luciana Fontes Pessôa Coorientadora: Heloisa Veiga Dias Alves

Rio de Janeiro

Março de 2018 


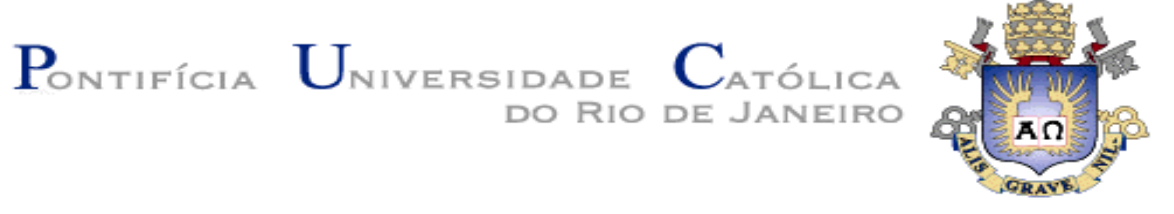

Maria Clara Veloso de Oliveira

\title{
Avaliação Neuropsicológica das Funções Executivas de Pré-Escolares
}

\begin{abstract}
Dissertação apresentada como requisito parcial para obtenção do grau de Mestre pelo Programa de Pós-Graduação em Psicologia (Psicologia Clínica) do Departamento de Psicologia do Centro de Teologia e Ciências Humanas da PUC-Rio. Aprovada pela Comissão Examinadora abaixo assinada.
\end{abstract}

\author{
Profa. Luciana Fontes Pessôa \\ Orientadora \\ Departamento de Psicologia - PUC-Rio \\ Prof. Jesus Landeira-Fernandez \\ Departamento de Psicologia - PUC-Rio \\ Profa. Ana Carolina Monnerat Fioravanti \\ Departamento de Psicologia - UFF \\ Profa. Monah Winograd \\ Coordenadora Setorial de Pós-Graduação \\ e Pesquisa do Centro de Teologia \\ e Ciências Humanas - PUC-Rio
}


Todos os direitos reservados. É proibida a reprodução total ou parcial do trabalho sem autorização da universidade, da autora e do orientador.

\section{Maria Clara Veloso de Oliveira}

Graduou-se em Psicologia na UNESA (Universidade Estácio de Sá) em 2014. Aluna de Mestrado em Psicologia Clínica, Departamento de Psicologia, PUC-Rio, início em 03/2015.

Ficha Catalográfica

Oliveira, Maria Clara Veloso de

Avaliação neuropsicológica das funções executivas de pré-escolares / Maria Clara Veloso de Oliveira; orientadora: Luciana Fontes Pessôa; co-orientadora: Heloisa Veiga Dias Alves. - 2018.

66 f. ; $30 \mathrm{~cm}$

Dissertação (mestrado)-Pontifícia Universidade Católica do Rio de Janeiro, Departamento de Psicologia, 2018.

Inclui bibliografia

1. Psicologia - Teses. 2. Desenvolvimento infantil. 3. Funções executivas. 4. Pré-escolares. 5. Avaliação neuropsicológica. I. Pessôa, Luciana Fontes. II. Alves, Heloisa Veiga Dias. III. Pontifícia Universidade Católica do Rio de Janeiro. Departamento de Psicologia. IV. Título. 
Para minhas filhas, Maria Luiza e Cecília, pela generosidade e pelo amor maior que existe. 


\section{Agradecimentos}

À Heloisa Dias Veiga Alves, amiga e pesquisadora admirável, pelo carinho e, acima de tudo, pelo suporte no enfrentamento de todas (tantas) as dificuldades. Pelo encorajamento diante das muitas impossibilidades que foram apresentadas.

À CAPES e à PUC-Rio, pelos auxílios concedidos, sem os quais este trabalho não poderia ter sido realizado.

Às minhas filhas Maria Luiza e Cecília, pela tolerância com a falta, pelo amor inesgotável, pelo conforto.

À minha mãe, pelo suporte necessário durante todo o percurso. À minha avó Zê, pelo amor e ao tio Danillo, pelo acolhimento.

À professora e orientadora, Luciana Fontes Pessôa, pelo acolhimento e pelo conhecimento compartilhado. 


\section{Resumo}

Oliveira, Maria Clara Veloso de; Pessôa, Luciana Fontes. Avaliação Neuropsicológica das Funções Executivas de Pré-escolares. Rio de Janeiro, 2018. 66p. Dissertação de Mestrado - Departamento de Psicologia, Pontifícia Universidade Católica do Rio de Janeiro.

O entendimento de que o desenvolvimento infantil acontece de maneira dinâmica entre fatores biológicos e ambientais sugere que essa fase constitui um período flexível, que pode ser aprimorado através de intervenções. Desta maneira, crianças em idade pré-escolar são simultaneamente vulneráveis às influências do meio e capazes de se beneficiar com intervenções precoces, apontando para a importância do estudo do desenvolvimento cognitivo nesta etapa da vida. $\mathrm{Na}$ literatura, as funções executivas são apresentadas como habilidades cognitivas flexíveis, necessárias para a adaptação do ser humano frente às novas situações, articuladas àquelas ações necessárias para alcançar determinado objetivo. Desta forma, o objetivo deste trabalho foi realizar uma revisão bibliográfica referente aos estudos que investigam os estágios iniciais do desenvolvimento destas funções e, a partir disto, elaborar uma proposta para medir as funções executivas de crianças em idade pré-escolar, apontando os benefícios dessas investigações para a área do desenvolvimento infantil. A partir da revisão de literatura, verificou-se a necessidade de publicações nacionais visando à adaptação e validação de instrumentos de avaliação neuropsicológica direcionados às etapas iniciais do desenvolvimento no ciclo vital. O presente estudo apresenta uma ferramenta alternativa que sirva de instrumento para a investigação destas funções ainda na primeira infância.

\section{Palavras-chave}

Desenvolvimento infantil; funções executivas; pré-escolares; avaliação neuropsicológica. 


\section{Abstract}

Oliveira, Maria Clara Veloso de; Pessôa, Luciana Fontes (Advisor). Neuropsychological Assessment of Executive Functions in Preschool Children. Rio de Janeiro, 2018. 66p. Dissertação de Mestrado Departamento de Psicologia, Pontifícia Universidade Católica do Rio de Janeiro.

The understanding that child development occurs through a dynamicinteraction between biological and environmental factors suggests that this phase is a flexible and amenable to improvements through interventions. In this context, pre-school children are simultaneously vulnerable to environmental influences and able to benefit from early interventions, pointing to the importance of understanding cognitive development at this stage of life. In the literature, executive functions are presented as flexible cognitive skills, necessary for the adaptation of the human being to the new situations, articulated to those actions necessary to reach a certain goal. Thus, the goal of this study was to carry out a bibliographic review of studies that investigate the initial stages executive function development and, from this, elaborate a proposal aiming to measure executive functions in preschool children, pointing out the benefits of these studies in the area of child development. Results indicated the need for national publications aiming at the adaptation and validation of neuropsychological assessment instruments targeting the initial stages of human development.

\section{Keywords}

Child development; executive functions; preschoolers; neuropsychological assessment. 


\section{Sumário}

1. Justificativa e Apresentação 9

2. Fundamentação Teórica 11

2.1. Funções Executivas 11

2.2. Neurobiologia das Funções Executivas 16

2.3. Maturação Cerebral e Desenvolvimento das Funções Executivas 20

2.4. Avaliação Neuropsicológica 24

2.4.1 Cultura e Avaliação do Desenvolvimento Infantil 26

2.4.2 Seleção de Instrumentos de Avaliação 28

2.5. Avaliação das Funções Executivas de Crianças em Idade Pré-escolar $\quad 30$

2.5.1. Memória de Trabalho 32

2.5.2. Controle Inibitório 33

2.5.3. Flexibilidade Cognitiva 36

$\begin{array}{ll}\text { 3.Objetivos } & 37\end{array}$

3.1. Objetivo Geral 37

$\begin{array}{ll}\text { 3.2. Objetivos Específicos } & 37\end{array}$

4. Metodologia 38

$\begin{array}{ll}\text { 5. Resultados } & 40\end{array}$

5.1. Avaliação das Funções Executivas de Pré-escolares 44

6. Discussão 55

7. Considerações Finais 58

8. Referências bibliográficas $\quad 60$ 


\section{Justificativa e Apresentação}

A identificação precoce de atraso no desenvolvimento poderia minimizar, ou, até mesmo, evitar posteriores conseqüências educacionais e sociais desfavoráveis (Landry et al., 2002). Mudanças biológicas e fisiológicas que ocorrem entre uma criança dependente de seus cuidadores e um adolescente autônomo representam o desenvolvimento infantil. Essas mudanças estão relacionadas às interações multidirecionais entre fatores biológicos e influências do meio. Desta forma, a primeira infância compreende um momento de grande risco para o desenvolvimento satisfatório das funções cognitivas, mas também de grande oportunidade, uma vez que o desenvolvimento do sistema nervoso neste período é extremamente plástico. Assim, crianças em idade pré-escolar são simultaneamente vulneráveis às influências do meio e capazes de se beneficiar com intervenções precoces, apontando para a importância de avaliações nessa fase do desenvolvimento (Fernald, 2009).

Instrumentos de avaliação neuropsicológica de pré-escolares, no Brasil, ainda são escassos (Alchieri \& Madruga, 2014). Hoje existe limitado número de instrumentos favoráveis, segundo o Conselho Federal de Psicologia (CFP), para aplicação clínica, que objetivam a avaliação do funcionamento neuropsicológico de crianças em idade pré-escolar no Brasil. Uma vez que as funções executivas têm grande valor adaptativo, imprescindíveis para o bom desenvolvimento escolar, social e psicológico, o papel limitado do psicólogo na saúde da primeira infância no Brasil representa um quadro que merece atenção. Caberia à comunidade científica esforços para que este cenário possa ser reinventado, através de estudos de adaptação e validação de instrumentos já bem divulgados na literatura internacional, ou mesmo, através da elaboração de novos instrumentos voltados, principalmente, para essa faixa etária. O presente trabalho foi desenvolvido a partir de um interesse particular em estudar a emergência dos processos cognitivos de crianças nos estágios iniciais do desenvolvimento.

Desta forma, a proposta deste trabalho foi apresentar uma alternativa para que profissionais da área reflitam sobre a importância da avaliação neuropsicológica na primeira infância, de maneira que possíveis atrasos no 
desenvolvimento possam ser identificados ainda em estágios iniciais, contribuindo para uma intervenção mais efetiva e um melhor prognóstico.

O interesse pela primeira infância se deve ao fato de esta etapa do desenvolvimento humano ser fundamentalmente crítica para o desenvolvimento de determinados aspectos cognitivos, como as funções executivas (Anderson, 2002). A partir de uma perspectiva integrativa do desenvolvimento humano, torna-se fundamental o entendimento das funções executivas em crianças com idade pré-escolar (Garon, Bryson \& Smith, 2008). Os primeiros cinco anos de vida representam um momento crítico para o desenvolvimento das funções executivas. Estas funções são fundamentais para o comportamento guiado a um objetivo, bem como favorecem a adaptação ao meio, a resolução de problemas, habilitando os indivíduos a responderem de forma mais adequada aos estímulos apresentados (Mesulam et al., 2002).

A avaliação neuropsicológica se propõe a investigar as funções cognitivas, como por exemplo, a linguagem, a atenção, a memória, as funções executivas, entre outros. Historicamente, a avaliação de crianças tem como objetivo identificar transtornos cognitivos ou comportamentais de ordem neurológica, auxiliando na identificação e no tratamento de possíveis disfunções neurológicas, de desenvolvimento, ou comportamentais (Barros \& Hazin, 2013).

Apesar de o entendimento de como funções executivas se desenvolvem, ainda existe um número limitado de instrumentos que se proponha a medir estas funções em crianças muito pequenas, em idade pré-escolar, quando comparado ao número de instrumentos de avaliação neuropsicológica disponíveis para outras fases do desenvolvimento humano. Neste contexto, o presente estudo se propôs a contribuir para o estudo das funções executivas, ainda em fase emergente. 


\section{Fundamentação Teórica}

\subsection{Funções Executivas}

O conceito de funções executivas (FE) é relativamente novo (aproximadamente 20-30 anos) e resultante de pesquisas neuropsicológicas sobre os efeitos de danos nos lobos frontais (Jurado \& Rosselli, 2007). É de aceitação mais ampla que as funções executivas compreendem habilidades "fluidas", ou processos que são engajados quando a pessoa é confrontada com uma situação nova, um problema ou um estímulo. Essas habilidades fluidas são distintas da cognição "cristalizada", ou do conhecimento de uma informação (por exemplo, vocabulário). Acredita-se que as FE incluam o controle da impulsividade, a habilidade para iniciar uma ação, para manter a atenção, e a persistência. Na literatura, as FE são apresentadas como habilidades cognitivas flexíveis, necessárias para a adaptação do ser humano frente às novas situações, articuladas àquelas ações necessárias para alcançar determinado objetivo (Garon, Bryson \& Smith, 2008). As FE são também apresentadas como controle executivo, ou controle cognitivo, e se referem aos processos mentais necessários para a concentração, quando o comportamento automático não se faz suficiente (Burgess \& Simons, 2005). Diferentes modelos são apresentados na literatura referentes ao conceito de FE. Com a intenção de mapear as definições relacionadas às FE, Packwood, Hodgets e Tremblay (2011) identificaram 68 subcomponentes dessas funções. A partir de técnicas estatísticas, estes autores conseguiram reduzir esses subcomponentes a cinco domínios: planejamento, memória de trabalho, flexibilidade cognitiva, inibição e fluência.

As funções executivas são muitas vezes entendidas como uma subcategoria das habilidades cognitivas, uma vez que processos cognitivos e emocionais estão envolvidos. Recentemente, Zelazo, Qu e Muller (2005) propuseram uma classificação das FE, dividindo-as em processos executivos "frios" (cold) e "quentes" (hot). Os processos frios seriam aqueles que não envolvem excitação emocional, compreendendo aspectos que envolvem o raciocínio lógico e abstrato, a memória de trabalho, planejamento e resolução de problemas. Já os processos quentes se relacionam aos aspectos emocionais, 
como por exemplo, a inibição ou o adiamento da gratificação (Hongwanishkul et al., 2005).

Miyake et al. (2000) argumentaram que parte da dificuldade em estudar componentes das FE se dá pelo fato de estes não serem puros. Afinal, ao analisar a literatura acerca destas funções, o autor identificou que os componentes mais comumente citados são a memória de trabalho, o controle inibitório (autocontrole, controle da interferência, atenção seletiva e inibição cognitiva) e a flexibilidade cognitiva (flexibilidade mental). Ainda de acordo com o autor, um modelo ideal das FE seria aquele onde seus componentes são parcialmente independentes, porém, correlacionados entre si. Lehto et al. (2003), por sua vez, utilizaram esse modelo num estudo com crianças entre 8 e 13 anos de idade, onde as medidas das FE foram agrupadas de acordo com estes três componentes: memória de trabalho, controle inibitório e flexibilidade cognitiva. A partir desses domínios/componentes, funções superiores serão construídas, tais como o raciocínio, a resolução de problemas e o planejamento (Collins \& Koechlin, 2012), fazendo com que as FE sejam de grande importância para o desenvolvimento cognitivo, social e psicológico. Assim como proposto por Miyake et al. (2000), neste trabalho serão revisados os conceitos de memória de trabalho, controle inibitório e flexibilidade cognitiva.

O termo "memória de trabalho" é apresentado pela ciência cognitiva como a função que se refere a um sistema de capacidade limitada, capaz de realizar o armazenamento e manipulação temporários de uma informação com o objetivo de responder a tarefas complexas, como o raciocínio, a compreensão e o aprendizado (Baddeley, 2000). A memória de trabalho envolve a retenção de uma informação na memória, de maneira que esta possa ser trabalhada mentalmente. Ou seja, se refere à manipulação de uma informação que não está mais presente a nível perceptual (Smith \& Jonides, 1999). Dois tipos de memória de trabalho são distinguidos segundo seu conteúdo - memória de trabalho verbal e não-verbal (visuoespacial). Sem esta função, não seria possível relacionar eventos anteriores aos posteriores, organizar itens mentalmente, incorporar novas informações ou fazer relações entre ideias. É a partir da memória de trabalho que nos tornamos capazes de manter um conhecimento conceitual, e não somente perceptual, para embasar nossas decisões (Diamond, 2013). 
De acordo com Barkley (1997), a memória de trabalho se refere à capacidade de manipular e manter uma informação na mente, à autoconsciência, entre outros. A autorregulação do afeto, da motivação e da estimulação, possibilita que o indivíduo se motive, ou se engaje, afetivamente em relação a um objetivo específico. A internalização da fala, ou o discurso interno, representa a maneira pela qual o sujeito realiza o autoquestionamento, a reflexão e o monitoramento antes de uma ação. Com a reconstituição, tornam-se possíveis as análises e as sínteses - onde a primeira fragmenta situações em partes, e a segunda recombina esses elementos de forma criativa. Após a elaboração deste modelo autorregulatório, Barkley (2001) adota uma perspectiva evolutiva das funções executivas, na qual estas são entendidas como exclusivas da espécie humana, como frutos de uma adaptação biológica resultante de uma competição interpessoal nos grupos. Desta maneira, deficit resultantes de lesões ou transtornos do desenvolvimento podem produzir um prejuízo adaptativo.

O modelo de memória de trabalho proposto por Baddeley (2002) foi o mais comumente encontrado durante a revisão. Este modelo compreende um executivo central e dois sistemas de armazenamento temporários da informação - a alça fonológica (phonological loop), responsável pelo armazenamento da informação acústica e/ou verbal, e o esboço visuoespacial (visual-spatial sketchpad), responsável pelo armazenamento da informação de mesmo nome. O executivo central é definido como um processo atencional (atenção concentrada, dividida e alternada) e compreende a manipulação ativa da informação armazenada pelos dois sistemas mencionados. Ambos os sistemas de armazenamento descritos são caracterizados por duas funções: armazenamento passivo e de articulação ativa (Baddeley, 2002). Desta forma, a alça fonológica e o esboço visuoespacial possibilitam 0 armazenamento temporário de informações auditivas e visuoespaciais, enquanto o executivo central desempenha o processamento geral das informações recebidas.

Além destes sistemas, Baddeley (2000) apresenta um terceiro, o buffer episódico, capaz de armazenar informações de maneira multidimensional, fornecendo uma interface temporária entre a alça fonológica, o esboço visuoespacial e a memória de longo prazo (LTM). É entendido que este sistema é controlado pelo executivo central, responsável por vincular informações provenientes de diferentes fontes, que mais tarde poderão ser recuperadas conscientemente. O buffer episódico irá servir como um modelo separado da 
memória de longo prazo, mas que constitui uma importante etapa da aprendizagem.

O controle inibitório se refere à capacidade de controlar a atenção, os pensamentos, comportamentos e/ou as emoções, de maneira a estar apto a realizar aquilo que é mais apropriado ou necessário em um determinado momento. Na ausência de tal controle, estaríamos à disposição dos impulsos, de antigos hábitos (por exemplo, respostas condicionadas), de maneira que os estímulos ambientais coordenariam nossa forma de atuar sobre o mundo (Diamond, 2013). O controle inibitório da atenção, ou simplesmente controle atencional, permite que possamos selecionar aqueles estímulos que nos são apresentados, focando em aspectos que escolhemos e suprimindo os demais, baseados em nossos objetivos (Theeuwes, 2010). Outro aspecto do controle das interferências remete à supressão das representações mentais (inibição cognitiva) e envolve a possibilidade de resistir diante de pensamentos ou memórias involuntárias - usualmente a serviço da memória de trabalho (Diamond, 2013). O autocontrole é outro aspecto do controle inibitório que envolve o controle da emoção, servindo à regulação do comportamento. Este controle está associado à disciplina necessária para conclusão de uma tarefa, e também se refere à capacidade de adiar uma gratificação qualquer em função de uma recompensa maior (Mischel et al., 1989). A existência desse controle é imprescindível para a realização de um projeto a longo prazo.

De acordo com a proposta de Barkley (1997), o controle inibitório estaria associado a três processos. Estes processos compreendem (a) inibição de uma resposta prepotente; (b) suspensão de uma resposta em curso; (c) inibição de distratores. São consideradas respostas prepotentes aquelas onde 0 reforçamento, negativo ou positivo, se faz presente. No que diz respeito à suspensão de uma resposta em curso, o controle inibitório irá possibilitar que ocorra um intervalo de tempo para a apresentação de uma resposta. A inibição de distratores, por sua vez, possibilita que durante o intervalo necessário para que ocorra uma resposta, um comportamento autodirecionado possa atuar. Alguns aspectos das funções executivas são favorecidos em função da atuação do controle inibitório: a autorregulação do afeto, a memória de trabalho e a fala internalizada, que atuam diretamente sobre o controle da resposta motora em função da execução de uma tarefa. 
No que diz respeito ao controle inibitório, a literatura sugere que durante o período pré-escolar as crianças gradualmente se tornam mais aptas a inibir um comportamento por um período de tempo mais prolongado, inibindo respostas automáticas e aquelas reforçadas. Entretanto, a habilidade de usar uma representação mental para regular o comportamento está apenas se iniciando durante este período do desenvolvimento (Garon, Bryson \& Smith, 2008). Sugere-se que conexões entre áreas pré-frontais, usadas no pensamento abstrato, e outras regiões cerebrais, como o córtex orbitofrontal e áreas límbicas, estão em pleno desenvolvimento durante o período pré-escolar (Thatcher, 1994).

A flexibilidade cognitiva é construída a partir dos dois domínios apresentados anteriormente, emergindo depois no desenvolvimento (Garon, Bryson \& Smith, 2008). Esta habilidade se relaciona à possibilidade de mudar perspectivas espaciais (por exemplo, visualizar um objeto a partir de outra orientação visuoespacial) ou interpessoais (ser capaz de usar o ponto de vista proveniente do outro). Para mudar perspectivas, nós precisamos inibir nossas perspectivas anteriores e ativar na memória de trabalho uma nova e diferente perspectiva - é neste sentido que essa função se apóia sobre aquelas apresentadas anteriormente. Outro aspecto da flexibilidade cognitiva envolve mudar a maneira como pensamos sobre algo, necessária para ajustar as demandas que nos são apresentadas (Diamond, 2013). 


\subsection{Neurobiologia das Funções Executivas}

Historicamente, modelos explicativos acerca da compreensão da relação entre o comportamento (processos mentais) e o funcionamento cerebral, transitam desde os primeiros achados arqueológicos das trepanações (7000 a.C.) até a conhecida década do cérebro, iniciada em 1990, onde avanços importantes foram realizados acerca da compreensão da relação entre o funcionamento psicológico e o cerebral. Alexsander Romanovich Luria (1991) apresenta, nesse sentido, a investigação de uma base cerebral que esteja associada aos processos mentais. Propõe uma alternativa em relação às posições localizacionistas e globalistas, inaugurando uma concepção de ciência em que existe uma concordância entre aspectos neurofisiológicos e a perspectiva humanista (Kristensen, Almeida \& Gomes, 2001). De acordo com esse autor, fatores externos (mediadores simbólicos, como a linguagem) exercem papel fundamental na organização dos sistemas cerebrais, apontando, ao mesmo tempo, para a existência de um princípio universal (biológico) e para a variabilidade cultural. Esta proposição se apóia na teoria desenvolvimentista apresentada por Vygotsky, onde a natureza e a cultura irão permear o desenvolvimento mental (Kotik-Friedgut, 2006).

Formas superiores do funcionamento cerebral humano não estão restritas a áreas específicas do cérebro, como acontece com as inferiores. De acordo com Luria (1991) o cérebro é formado por sistemas funcionais, caracterizados pela mobilidade de suas partes constituintes, não apenas por sua complexidade estrutural. Este autor identifica três unidades funcionais que irão reger a complexidade do funcionamento cerebral. A primeira seria responsável pela regulação do tono ou vigília; a segunda unidade seria receptora, mediando o contato com o meio, armazenando e processando as informações provenientes dos canais sensoriais; a terceira seria a responsável pela programação e regulação da atividade mental. Essa organização funcional foi organizada pelo autor em três zonas corticais: primária, secundária e terciária (Hazin et al., 2010).

As áreas primárias (ou áreas de projeção) apresentam uma relação com as funções sensoriais e motoras, localizadas em diferentes regiões corticais, divididas de acordo com a sua especificidade. As áreas de associação são definidas como aquelas que não apresentam relação direta com as funções 
sensitivas e motoras, ocupam porções extensas da área cortical e possuem papel relevante no que diz respeito ao desenvolvimento das funções psicológicas superiores. São divididas em (a) áreas de associação secundárias, de caráter unimodal, apresentando relação indireta com algum subtipo específico de modalidade sensorial ou motora; e (b) áreas de associação terciárias, que se encontram no ápice da hierarquia cortical em função da sua complexidade funcional - são supramodais, ou seja, não têm relacionamento específico com nenhuma modalidade sensorial - recebem e integram as informações provenientes do processamento sensorial, já elaboradas pelas regiões secundárias, possibilitando ao indivíduo criar estratégias comportamentais. As áreas terciárias (ou heteromodais) possibilitam a coerência do funcionamento cognitivo e são divididas em três áreas: (1) área pré-frontal, localizada no lobo frontal e responsável pelas estratégias comportamentais que irão servir às demandas ambientais, à atenção e ao controle emocional; (2) área temporoparietal terciária, que serve à percepção espacial e à formação do esquema corporal, ao reconhecimento de faces, vozes e objetos; (3) áreas límbicas, responsáveis pela manutenção da memória e do comportamento emocional (Hazin et al., 2010). As funções executivas estão associadas ao funcionamento das áreas terciárias.

No que diz respeito às estruturas cerebrais subjacentes às funções cognitivas superiores, resultados de estudos que utilizaram neuroimagem e avaliação neuropsicológica das funções do lobo frontal apontaram para módulos especializados, localizados em diferentes áreas do córtex frontal, com funções específicas, indicando que o papel do lobo frontal na regulação da atividade mental é evidente (Thompson-Schill, Bedny \& Goldberg, 2005).

As FE possuem um sistema neural disperso, no qual o córtex pré-frontal (CPF) irá mediar os diferentes aspectos do funcionamento executivo, porém é necessária a atuação de distintos circuitos neurais diante das demandas executivas. O CPF é composto por níveis de especialização funcional, em que cada um destes sistemas neurais remete a aspectos comportamentais e cognitivos específicos - os circuitos dorsolateral, lateral orbitofrontal e o cíngulo anterior (Malloy-Diniz et al., 2008). No que diz respeito ao desenvolvimento desta área cerebral, tanto a nível filogenético (evolução da espécie), quanto a nível ontogenético (desenvolvimento do indivíduo), o CPF é a última área cerebral a se desenvolver (Goldberg, 2002). Esta região cerebral é precariamente 
desenvolvida em primatas não humanos, representando uma característica fundamental da espécie humana (Coolidge \& Wynn, 2001), razão pela qual o lobo frontal seria apresentado como o "órgão da civilização" por Goldberg (2002). Luria (1991) entende as FE como funções superiores que atuam nas formas complexas da atividade humana que objetivam uma meta. A interconectividade característica do CPF possibilita que este desempenhe o papel de regulador das outras estruturas cerebrais, atuando como um coordenador das demais funções (Goldberg, 2002).

De acordo com os modelos teóricos que apresentam as FE em dois grupos, as FE frias são caracterizadas por componentes abstratos e lógicos, associados à porção pré-frontal dorsolateral (atenção, flexibilidade cognitiva, memória de trabalho, planejamento e resolução de problemas). As FE quentes são associadas ao circuito orbitofrontal e apresentam componentes emocionais e motivacionais, como a habilidade necessária para considerar conseqüências a longo prazo ou inibir comportamentos indesejáveis (Malloy-Diniz et al., 2010). No que diz respeito aos componentes das FE aqui explorados, circuitarias neurais específicas podem ser apresentadas.

De acordo com Baddeley (2007), a memória de trabalho funciona como um depósito temporário de manipulação das informações necessárias para o desempenho de funções cognitivas complexas, servindo também ao processamento linguístico. Ainda que grande parte do processamento linguístico seja automática, o prejuízo nas FE interfere negativamente neste processamento. Para um maior entendimento acerca destes processos cognitivos, as neurociências vêm permitindo, através das técnicas de imageamento cerebral, a investigação das relações entre as habilidades em desenvolvimento e a maturação do córtex cerebral (Goldman-Rakic, 1987). Estudos realizados com crianças e adolescentes indicam que tarefas simples implicam que determinada informação seja mantida mesmo após um certo período de tempo, enquanto tarefas mais complexas exigem o resgate e a manipulação da informação (Gathercole, Pickering \& Ambridge, 2004). Estudos de neuroimagem dão suporte a esta distinção de funções durante a realização das tarefas, sugerindo diferentes padrões de ativação cerebral para tarefas mais simples ou mais complexas, onde uma exige o armazenamento da informação, enquanto a outra requer a manipulação do conteúdo armazenado (Smith \& Jonides, 1999). Para cada sistema de armazenamento, a função passiva está associada à ativação de áreas posteriores do cérebro, onde o estímulo é 
inicialmente percebido, enquanto a articulação ativa da informação está associada a distintas áreas frontais, como a área de Broca (Baddeley, 2002). A execução de tarefas que exigem o resgate e a manipulação da informação indicam a ativação de outras áreas cerebrais associadas ao controle atencional, localizadas no córtex cingulado anterior e pré-frontal dorsolateral (Smith \& Jonides, 1999).

A maturação cerebral necessária para o satisfatório desempenho das FE ocorre ainda na primeira infância, apontando para a relevância do estudo destas funções nesta etapa do desenvolvimento humano (Huizinga, Dolan \& Van Der Molen, 2006). A mielinização das áreas pré-frontais, necessária para a transmissão mais eficaz e veloz dos impulsos nervosos, se inicia na infância e possibilita a integração entre os processos cognitivos, porém as habilidades executivas irão manter seu desenvolvimento até a idade adulta. Nos primeiros anos de vida é comum observar que o comportamento da criança está mais relacionado à características impulsivas, guiadas por estímulos (Tonietto et al., 2011). O controle inibitório, por exemplo, se desenvolve de forma mais rápida a partir de um ano de idade até os seis anos; já habilidades como a flexibilidade cognitiva e o planejamento apresentam melhora entre os quatro e cinco anos de idade (Natale, 2007). 


\subsection{Maturação Cerebral e Desenvolvimento das Funções Executivas}

O desenvolvimento do sistema nervoso se inicia muito cedo no embrião, por volta da $3^{\text {a }}$ à $4^{\underline{a}}$ semana pós-fecundação. Durante a diferenciação neural, o corpo celular do neurônio (soma) irá aumentar em volume e projetará prolongamentos (dendritos - elementos receptores dos impulsos nervosos - e axônio - elemento emissor de impulsos nervosos), até que a célula adquira a maturidade característica e seja capaz de gerar, receber e transmitir informações (Lent, 2001). Essas informações são transmitidas através de sinapses, que permitem a passagem do impulso nervoso entre as células. O cérebro da criança possui uma grande quantidade de sinapses e somente a partir da formação das redes neurais processos mais complexos, como a aprendizagem, o raciocínio lógico, a abstração, o planejamento, serão possíveis. O desenvolvimento cerebral é plástico, ou seja, irá se reorganizar de acordo com padrões e sistemas de conexões sinápticas que servirão à adequação do crescimento do organismo diante das demandas ambientais, proporcionando novas capacidades intelectuais e comportamentais durante a infância. As células do sistema nervoso ainda em processo de maturação têm maior capacidade de adaptação. Desta forma, com o avanço da idade e a maturidade destas células irá ocorrer a diminuição da neuroplasticidade (Pinheiro, 2007).

Os neurônios irão se organizar em circuitarias que constituirão as regiões corticais que, ao se interligarem, formarão sistemas com níveis de complexidade progressivamente mais elevados. Neste arranjo, a atuação de um neurônio irá depender do conjunto de outros neurônios no qual este se insere; a funcionalidade do sistema, por sua vez, dependerá de como os conjuntos se influenciam mutuamente e a contribuição de cada conjunto para o funcionamento do sistema a que pertence dependerá da sua localização. Assim, a especialização cerebral será consequência da localização de um conjunto de neurônios dentro de um macrossistema (Damásio, 1996). O último estágio da maturação ontogenética do sistema nervoso é caracterizado pelo processo de mielinização, que se inicia ainda na vida intrauterina (por volta do 6ำ mês de gestação), se intensificando após o nascimento (por volta dos dois anos de idade) e segue seu curso até a idade adulta (Reed, 2005). A mielina é uma substância lipoproteica que irá revestir o axônio, formando uma bainha isolante, que resultará numa maior velocidade na propagação do impulso nervoso, assim como sua eficácia durante a transmissão da informação. Regiões corticais com 
mielinização precoce são associadas às análises sensoriais, enquanto aquelas com mielinização tardia serão responsáveis por processos cognitivos superiores, como as funções executivas (Kolb \& Whishaw, 2002).

As funções executivas se desenvolvem durante a primeira infância, à medida que ocorre o desenvolvimento do lobo frontal (Anderson, 2002). O engajamento das FE habilita o ser humano a adaptar-se a diferentes contextos. Os primeiros cinco anos de vida representam um momento crítico para o desenvolvimento destas funções, essenciais para o comportamento guiado a um objetivo, bem como favorecem a adaptação ao meio, a resolução de problemas, habilitando os indivíduos a responder de forma mais adequada aos estímulos apresentados (Mesulam et al., 2002). O desenvolvimento das FE representa um importante marco adaptativo da espécie humana (Malloy-Diniz et al., 2008), essas habilidades são fundamentais diante de demandas ambientais que exijam flexibilidade ou adaptação, também comumente observadas no contexto escolar (Dias, Menezes \& Seabra, 2010).

Durante muito tempo acreditou-se que crianças pequenas não apresentavam funções executivas. Essa concepção estava baseada no longo processo de maturação do córtex pré-frontal, muitas vezes considerado "funcionalmente silencioso". Atualmente, sabe-se que o desenvolvimento de tais funções se inicia nessa fase e segue seu curso até a idade adulta (Huizinga \& Van Der Molen, 2006). O desempenho das FE parece melhorar ao longo dos anos de desenvolvimento, indicando como períodos críticos desse desenvolvimento a fase entre o nascimento e os 2 anos de idade, a fase dos 7 aos 9 anos, e mais adiante, entre os 16 e os 19 anos de idade (Anderson, Northam, Wrennall \& Hendy, 2001). Em crianças de até 2 anos de idade os processos das FE mais comumente citados são a memória de trabalho, a inibição do comportamento e a atenção sustentada ou seletiva (Carlson, 2005).

Zelazo, Qu e Müller (2005) propuseram que durante o período préescolar a representação de uma regra, ou uma informação, se dá de forma hierárquica, de maneira que o erro de perseveração ocorre nessa etapa da vida em função de a criança não possuir uma forma integrada de regras incompatíveis. Esta característica pode resultar na discrepância entre o que se sabe e o que se faz. Já no final do período pré-escolar as crianças se tornam mais hábeis em refletir sobre regras, integrando os elementos conflituosos de um aprendizado num sistema mais complexo de regras. 
O controle inibitório do comportamento é desproporcionalmente difícil para crianças na primeira infância (Luna, 2009). O desenvolvimento do controle inibitório parece ser preditivo de consequências tardias na vida do indivíduo. Moffitt et al. (2011) realizaram um estudo longitudinal, observando que crianças que apresentaram um melhor desempenho em tarefas de controle inibitório aos 3 e 11 anos de idade (por exemplo, que se distraiam com menos facilidade, sejam mais persistentes e menos impulsivas), na adolescência eram menos propensas a fazer escolhas de risco ou a usar drogas. Aos 30 anos de idade, esses sujeitos também se mostraram mais satisfeitos com metas e objetivos alcançados, em comparação com aqueles sujeitos que tiveram um pior desempenho avaliado na infância. Assim como o controle inibitório, a habilidade para reter uma informação se desenvolve muito precocemente. Mesmo bebês e crianças pequenas apresentam essa capacidade, chegando a manter um ou dois itens na mente durante certo período de tempo (Nelson et al., 2012). Contudo, a habilidade para manter um número maior de itens ou para fazer a manipulação destes (por exemplo, reorganizar representações mentais dos objetos por tamanho) mostra uma progressão de desenvolvimento mais prolongada (Cowan et al., 2011).

A amplitude e a profundidade dos comportamentos que podem ser avaliados em uma criança aumentam com a idade. Os avanços na comunicação, bem como em outras habilidades, durante os primeiros anos de vida, irão prover formas adicionais de testagem (Snow \& Van Hemel, 2008). O entendimento de que o desenvolvimento infantil acontece de maneira dinâmica entre fatores biológicos e ambientais sugere que essa fase constitui um período flexível, que pode ser aprimorado através de intervenções. A primeira infância compreende um momento de grande risco, mas também de grande oportunidade, uma vez que o desenvolvimento do sistema nervoso neste período é extremamente plástico. Desta maneira, crianças em idade pré-escolar são simultaneamente vulneráveis às influências do meio e capazes de se beneficiar com intervenções precoces, apontando para a importância de avaliações nessa fase do desenvolvimento (Fernald, 2009).

O desenvolvimento do cérebro constitui um processo contínuo de construção, organização e aprimoramento de redes neurais em resposta aos estímulos externos (Nelson et al., 2012), que acontece de forma paralela ao desenvolvimento da complexidade das estruturas mentais (Piaget, 1954). De acordo com Fischer e Rose (1994), quando, ao longo do desenvolvimento 
cognitivo, uma nova habilidade é aprendida, acontece uma forma de "competição" entre esta e aquelas previamente existentes. A partir disso, gradualmente, enquanto a nova habilidade é integrada aos sistemas cognitivos existentes, esta habilidade se torna mais coordenada com outras existentes. As grandes mudanças que ocorrem durante o desenvolvimento envolvem a coordenação destas habilidades com sistemas mais complexos, onde esse sistema representa mais que a soma de habilidades. Desta forma, o desenvolvimento das FE ilustra esse processo, onde os componentes destas funções são desenvolvidos, a partir de funções cognitivas mais simples e constituem o resultado da coordenação destas (Garon, Bryson \& Smith, 2008). 


\subsection{Avaliação Neuropsicológica}

As últimas décadas do século $\mathrm{XX}$ proporcionaram o avanço das técnicas de imageamento cerebral e, desta forma, os exames hoje utilizados permitem maior precisão diagnóstica, bem como fornecem informações acerca da localização da causa de doenças. O objetivo diagnóstico e localizacionista se fez presente antes do surgimento das técnicas de neuroimagem, quando somente era possível realizar estudos de pacientes lesionados. Paul Broca, em 1861, realizava estudos post mortem para confirmar suas hipóteses. As neurociências, hoje, envolvem campos de pesquisa como a neurologia, a genética, a psiquiatria e a neuropsicologia (Malloy-Diniz et al., 2010). A neuropsicologia irá ocupar-se da complexidade da organização cerebral e sua relação com a cognição e o comportamento, em populações clínicas ou dentro do desenvolvimento típico. A neuropsicologia clínica, como ciência aplicada, irá estudar a expressão comportamental ocasionada por disfunções cerebrais (Lezak et al., 2004), visando o desenvolvimento de técnicas de exame e diagnóstico das disfunções cognitivas e comportamentais (Stuss \& Levine, 2002).

O processo de avaliação neuropsicológica conta com um método que visa investigar funções cognitivas e comportamentais, através da aplicação de exames quantitativos e qualitativos, além de entrevistas, com a intenção de planejar uma abordagem terapêutica adequada (reabilitação). Hoje, a neuropsicologia tem como desafio buscar a adaptação cultural dos métodos de testagem, uma vez que a maioria destes métodos está disponível em língua inglesa (Malloy-Diniz et al., 2010). A psicometria contribui para o desenvolvimento da neuropsicologia, através da construção de uma metodologia que possibilitará o desenvolvimento de testagens, privilegiando as amostragens e a padronização culturais. O neuropsicólogo clínico, se valendo dos avanços da psicometria, irá correlacionar as alterações observadas durante o processo de avaliação e as possíveis áreas cerebrais envolvidas, através de testes e tarefas neuropsicológicas.

A psicometria é a área da psicologia interessada em avaliar a efetividade de uma medida que avalia características psicológicas (ou domínios, como a linguagem, o desenvolvimento cognitivo e etc.) (Fernald, 2009). As análises psicométricas são principalmente usadas para determinar a confiabilidade e a validade de uma avaliação. A confiabilidade refere-se a quão consistentemente 
uma medida produz resultados similares para uma criança, ou um grupo de crianças, com medidas que são repetidas durante o tempo. Isso se baseia na aceitação de que indivíduos (ou grupo de indivíduos) mostram alguma estabilidade sobre um comportamento que está sendo avaliado. Entretanto, existe tipicamente alguma variação de pontuação nos testes. A confiabilidade de um teste pode ser aumentada assegurando que este teste é administrado de maneira uniforme e sob condições onde os indivíduos têm a capacidade de produzir seu melhor desempenho. A validade refere-se ao grau de precisão que uma medida tem para avaliar aquilo que se propõe, sejam comportamentos ou habilidades que refletem o conceito a ser testado. A maioria dos testes desenvolvidos passa por um exame rigoroso para assegurar que o teste é confiável e válido nas populações onde são desenvolvidos (Fernald, 2009).

No que diz respeito à avaliação neuropsicológica de crianças, é de grande importância considerar a fase do desenvolvimento em que a criança se encontra. A fase pré-escolar representa um estágio relevante para o desenvolvimento humano, onde habilidades cognitivas fundamentais são desenvolvidas. Em crianças nesta fase, a testagem neuropsicológica é indicada quando há dificuldades nas habilidades cognitivas ou atraso do desenvolvimento neuropsicomotor. É possível com esta avaliação identificar deficit e habilidades preservadas, possibilitando o planejamento de reabilitação (Ferreira et al., 2010). 


\subsubsection{Cultura e Avaliação do Desenvolvimento Infantil}

O desenvolvimento do indivíduo se caracteriza pela transição do comportamento natural ao cultural, onde as funções psicológicas primárias serão atravessadas pela dimensão simbólica oferecida pelo meio. A porção cultural que irá permear esse desenvolvimento se inaugura quando a criança se depara com o reconhecimento do outro, agente intencional como ela própria, a partir de onde irá imitar o uso dos meios e instrumentos culturais disponíveis (Vygotsky, 1991). A linguagem ganhará neste momento o papel fundamental de mediador simbólico que irá transformar os processos psicológicos inferiores (funcionamento unimodal) em redes complexas capazes de atribuir significados (funcionamento polimodal), culminando na emergência da consciência (Hazin et al., 2010).Cada cultura possui uma série de valores no que se refere às habilidades que as crianças devem desenvolver e quando isso deve acontecer. Algumas habilidades podem emergir precocemente, sendo valorizadas e encorajadas em uma cultura particular. Entretanto, isso não significa que tal habilidade não irá emergir em algum momento. Esses padrões culturais específicos devem ser considerados ao se avaliar a validade de uma medida (Fernald, 2009).

Cultura se refere a uma série de crenças, valores, objetivos, atitudes e atividades que guiam a maneira como determinado grupo de pessoas vive (Payne \& Taylor, 2002). Uma cultura particular é moldada a partir de fatores estruturais, tais como geográficos, religiosos, políticos e econômicos, acesso a sistemas educacionais e de saúde, e a tecnologia disponível. Práticas e ideias referentes ao desenvolvimento infantil estão intimamente relacionadas a esses ideais culturais. Estudos transculturais pretendem distinguir quais habilidades são universais e quais estão relacionados a uma cultura específica (Fernald, 2009).

O desenvolvimento infantil é entendido como a fase da vida da criança onde ocorrem transformações psicológicas e biológicas, transformando-a de um bebê dependente a um adolescente com certa autonomia (Fernald, 2009). Dentre as mudanças que ocorrem nesse período estão o desenvolvimento da linguagem, das habilidades cognitivas (por exemplo, pensamento simbólico e memória), das habilidades socioemocionais (a empatia e a interação com o outro), e das habilidades motoras (sentar, correr e movimentos mais complexos). 
Atualmente é entendido que o desenvolvimento é um processo que não é determinado independentemente pela natureza (Fernald, 2009). As transformações que acontecem na vida da criança resultam de interações multidirecionais entre fatores biológicos (genes, maturação cerebral, etc) e as influências do meio (características culturais) através do tempo (Shonkoff \& Phillips, 2000). Desta forma, a primeira infância é caracterizada como um período de grandes mudanças biológicas e comportamentais (Shonkoff \& Marshall, 2000) e o desenvolvimento cerebral, associado às interações com o meio, cria avanços fenomenais nas habilidades das crianças.

Novas habilidades irão surgir progressivamente na criança, muitas vezes sucessivamente, de maneira que o desenvolvimento de um domínio será fundamental para o desenvolvimento de outro. Igualmente, crianças que tendem a desenvolver lentamente determinado domínio cognitivo (por exemplo, compreensão da linguagem), poderão apresentar uma capacidade limitada para desenvolver outros aspectos cognitivos, como a realização de tarefas cognitivas que requerem habilidades linguísticas, por exemplo. As habilidades cognitivas envolvem habilidades analíticas, de resolução de problemas, memória, e habilidades matemáticas (Johnson, 1998). Em bebês e crianças pequenas, o desenvolvimento cognitivo envolve resolução de problemas com objetos e o entendimento rudimentar de propriedades matemáticas (Kuhn \& Siegler, 1998). 


\subsubsection{Seleção de Instrumentos de Avaliação}

O primeiro passo para selecionar alguma medida é ter claro o propósito da avaliação. A avaliação do desenvolvimento de crianças pode ser conduzida por diversas razões: para planejar intervenções e serviços; para monitorar ou avaliar o impacto da infância para programas educacionais; para investigar o efeito de intervenções ou programas específicos de interesse; ou para diagnosticar e avaliar o progresso de uma criança. Desta forma, a análise da testagem deve estar claramente associada aos objetivos da avaliação, que em troca ajudarão a guiar em relação a qual domínio o indivíduo será avaliado, os tipos de testes que serão utilizados, e as abordagens que serão utilizadas para interpretar a informação obtida (Snow \& Van Hemel, 2008).

Existem três métodos para a coleta de informação acerca do desenvolvimento de bebês e crianças pequenas: 1) testar diretamente a criança; 2) obter relatos dos cuidadores (ou outros) sobre o comportamento e as habilidades da criança; e 3) observação das atividades cotidianas da criança (Snow \& Van Hemel, 2008). Muitos testes combinam dois ou mais modos de avaliação. Cada um desses métodos de avaliação individual pode ser agregado, através dos grupos, para criar uma medida base da população. Neste caso, é possível fazer uma amostra de crianças, ao invés de testar todas, fato que pode ser particularmente útil para o impacto de uma larga escala de avaliações de programas nacionais ou de intervenção.

Os testes de avaliação direta são realizados a partir da apresentação de um estímulo para evocar respostas, de maneira que essas completem tarefas ou atividades. Os avaliadores são usualmente capacitados para administrar e pontuar o teste. Classificações e relatórios são escalas, ou checklists, que serão completados por informantes que conhecem bem a criança, como os pais, cuidadores ou professores. Os informantes irão responder questões sobre as habilidades da criança, mas essa não será avaliada diretamente (Fernald, 2009).

Medidas de observação exigem um observador treinado, que documente os comportamentos de uma criança, em ambiente doméstico ou institucional. Existem três tipos de medidas observacionais geralmente utilizadas: a) observação naturalista, onde o observador irá registrar o comportamento da criança em ambiente natural - úteis para identificar características do meio; b) observações de amostras, onde um comportamento específico pode ser definido 
e a freqüência desses comportamentos é observada em um período de tempo; c) situações estruturadas, onde tal situação é criada, e onde o comportamento da criança é observado nesta situação (Fernald, 2009).

Os testes de rastreio são avaliações breves usadas para identificar - com algum nível de certeza - crianças que possuem certo risco de problemas de desenvolvimento, em um ou mais domínios (Glascoe, 2005). Os testes de rastreio contêm amostras de itens por domínios (isto é, eles não avaliam a habilidade por completo) e em função disso estes são usados para classificar as crianças em categorias como "com atraso", "com risco de atraso", ou "dentro dos limites normais" de acordo com a idade. Podem ser feitos por testagem direta com a criança, por relatório ou ambos e não têm propósitos diagnósticos.

Os testes de habilidades incluem aqueles designados a avaliar o nível máximo de uma habilidade em crianças de qualquer idade. Estes testes são geralmente de aplicação direta. A avaliação de uma habilidade disponibiliza informações detalhadas sobre o desenvolvimento da criança - as pontuações são freqüentemente padronizadas. A vantagem desse tipo de teste se refere à possibilidade dos escores serem usados para comparar os níveis de desenvolvimento da criança de maneira mais precisa, e estes escores podem ser mais sensíveis aos efeitos do tratamento, quando comparados aos testes de rastreio. Os escores das crianças pequenas (menores de 3 anos de idade) são tipicamente rotulados como quociente de desenvolvimento, uma vez que eles ainda podem sofrer mudanças, enquanto para crianças mais velhas os escores são chamados de quociente de inteligência (QI), uma vez que esses se tornam mais preditivos do desenvolvimento futuro. Alguns testes são diagnósticos, avaliando habilidades específicas como a comunicação, e podem ser usados para recomendar tipos específicos de assistência (Fernald, 2009). Dentre os domínios avaliados em crianças com idade pré-escolar, estão as habilidades cognitivas, como as funções executivas. 


\subsection{Avaliação das Funções Executivas de Crianças em Idade Pré- escolar}

Diamond (2002) relatou que pouco se sabe sobre as funções frontais na faixa etária dos 12 aos 36 meses de idade, quando comparado ao que já se conhece dessas funções em outros períodos da vida. O córtex frontal está ativo e em fase de maturação durante a primeira infância (Bell, 2001) e esta maturação, observada também através da atividade elétrica cerebral, está associada à melhora do desempenho em tarefas como $A$-not- $B$, desenvolvida por Piaget (Bell \& Fox, 1997). Estudos desenvolvidos por Diamond e GoldmanRakic (1989), demonstraram que o desempenho satisfatório na tarefa $A$-not- $B$ depende da maturação e integridade do córtex pré-frontal dorsolateral. Propôs ainda, que as habilidades necessárias para a resolução desta tarefa incluem a capacidade de manter uma representação na memória e a capacidade de inibir uma resposta motora (Diamond, 1990).

O bom desempenho de crianças na tarefa $A-n o t-B$, que envolve controle inibitório $(\mathrm{Cl})$ e memória de trabalho $(\mathrm{MT})$, foi relacionado à alta ativação elétrica da área frontal do cérebro em um estudo realizado com EEG (Bell \& Fox, 1997), enquanto crianças com mau desempenho nesta mesma tarefa não apresentaram aumento da ativação elétrica desta mesma área (Bell, 2001). No estudo realizado por Bell e Fox (1992), foram avaliadas as relações entre os registros do EEG e o desenvolvimento da habilidade, para desempenhar de forma satisfatória, duas tarefas cognitivas atribuídas ao funcionamento do lobo frontal em crianças de 7 a 12 meses de idade. O objetivo desse estudo foi examinar as relações entre os diferentes registros da atividade elétrica do cérebro e o desenvolvimento das habilidades relacionadas ao lobo frontal, a partir de tarefas cognitivas $(A-n o t-B)$. Os resultados demonstraram que, mesmo em crianças desta faixa etária, existe uma relação entre a atividade elétrica no lobo frontal e o desempenho na tarefa $A-n o t-B$.

O estudo desenvolvido por Allan et al. (2015) demonstrou que a atenção e as funções executivas representam distintos construtos durante o período préescolar. Ainda que esses construtos apresentem relações bem específicas, contribuindo, por exemplo, para um comportamento adequado em sala de aula e o bom desempenho acadêmico durante este período do desenvolvimento. Miller e Marcovitch (2015) apontaram que o engajamento das FE durante o segundo 
ano de vida se mostra mais evidente aos 18 meses de idade, ocorrendo uma melhora significativa no desempenho das crianças avaliadas a partir de tarefas de FE. O melhor desempenho aos 18 meses de idade foi demonstrado de forma preditiva em testagens de FE e de linguagem que ocorreram aos 14 meses, dando suporte à ideia de que o desenvolvimento das FE está fortemente relacionado ao desenvolvimento da habilidade representacional. 


\subsubsection{Memória de Trabalho}

Das tarefas direcionadas às crianças, para avaliar a manutenção de uma informação, ou a memória de trabalho, aquelas do tipo delayed response task são as mais comumente utilizadas. Nesse tipo de tarefa um objeto é escondido em uma de duas localizações possíveis. A localização na qual o objeto é escondido é aleatoriamente alterada de uma sequência para outra. Estudos indicam que a capacidade de manter uma representação mental, após um período de tempo, está presente mesmo em bebês com menos de 6 meses de idade (Johnson et al., 2005). O que parece se desenvolver a partir dessa idade é o aumento da duração do tempo em que a representação mental é mantida, além do número de informações que podem ser mantidas (Pelphrey \& Reznick, 2003). A partir dos 2 anos de idade, a habilidade de manter uma representação mental, após certo período de tempo, é avaliada através de tarefas com maior tempo de duração (span tasks). Estudos transversais apontam que o número de itens que podem ser mantidos durante uma tarefa realizada com crianças de 3 a 5 anos de idade aumenta consideravelmente, em tarefas como Word Span task, que avaliam a memória de trabalho verbal (Espy \& Bull, 2005). Habilidades mais complexas da memória de trabalho, como aquelas que requerem a recuperação e a manipulação de uma informação, se desenvolvem por volta dos 2 anos de idade e perduram durante o período pré-escolar (Alloway et al., 2004).

No Word Span task, baseado no subteste span de dígitos do WISC-III, o avaliador apresenta a criança uma lista de palavras (faladas) e a criança é solicitada a repetir as palavras que foram ditas. Assim como no subteste do WISC-III, o número de palavras aumenta de um nível para outro, chegando a no máximo 6 palavras. Existem duas seqüência de palavras em cada nível, onde a criança deve reproduzir ao menos uma seqüência para avançar para o nível seguinte. Na fase de "ordem direta" da tarefa, as crianças devem reproduzir as palavras na ordem dita pelo avaliador. Na fase de "ordem inversa", as palavras devem ser repetidas inversamente a ordem apresentada pelo avaliador. Já no Spatial SpanTask, 


\subsubsection{Controle Inibitório}

O controle inibitório se refere a uma habilidade cognitiva que envolve restringir, ou evitar, inclusive, uma resposta motora. Este é provavelmente o componente das FE mais comumente estudado em crianças no período préescolar (Garon, Bryson \& Smith, 2008). Um dos desafios presentes na compreensão do desenvolvimento do controle inibitório é o grande número de tarefas que pretendem medir essa função, de forma que muitas das tarefas propostas para medir o controle inibitório também envolvem a atuação da memória de trabalho. Estas tarefas avaliam a habilidade da criança em se utilizar de uma regra em função de controlar o comportamento. Alguns autores apontam para a importância de se disntinguir tarefas que medem apenas o controle inibitório daquelas que se utilizam também da função da memória de trabalho (Diamond, 2002). Garon, Bryson e Smith (2008) se utilizaram dos termos "tarefa de controle inibitório simples" (simple response inhibition tasks), para aquelas tarefas que envolvem mínima atuação da memória de trabalho, e "tarefa de controle inibitório complexa" (complex response inhibition tasks) para aquelas que demandam moderadamente a atuação da memória de trabalho.

Nas tarefas simples de controle inibitório a criança deve adiar uma resposta preponderante ou automática enquanto executa a tarefa. Um exemplo deste tipo de tarefa é o Gift Delay task, onde é dito à criança que o avaliador gostaria de Ihe dar um presente, mas teve que embrulhá-lo primeiro. É solicitado que a criança se sente em uma cadeira, de frente para o avaliador, porém olhando para outro lado, enquanto o avaliador embrulha o presente. $O$ avaliador então utiliza um processo padrão de 60 segundos para fazer o embrulho e então entrega o presente para a criança.Se a criança vira a cabeça para espiar o avaliador em mais de 90ㅜㄹ é registrado em que momento isso acontece. Se a criança vira todo o corpo para espiar, antes do período de 60 segundos se encerrar, o momento em que isso ocorre também é registrado. A criança é alertada por até 3 vezes que não deve espiar o avaliador (Allan \& Lonigan, 2011).

As tarefas complexas de controle inibitório envolvem seguir uma regra arbitrária e responder de acordo com esta, inibindo a resposta dominante. Muitas destas tarefas exigem um controle verbal sobre o comportamento. Na tarefa bear and dragon, por exemplo, as crianças são orientadas a reproduzir a ação de um fantoche enquanto inibem as ações sugeridas pelo outro fantoche (Reed, Pien \& 
Rothbart, 1984). Desta forma, as crianças devem reprimir a inclinação natural de reproduzir o que lhes é dito, o que se torna particularmente difícil durante uma execução já em andamento. De acordo com Carlson (2005) esta habilidade se desenvolve rapidamente por volta dos 3 anos de idade - enquanto $51 \%$ das crianças com menos de 3 anos conseguem executar de forma satisfatória a tarefa, $76 \%$ das crianças com mais de 3 anos são capazes de executá-la de maneira satisfatória, sugerindo o aumento da capacidade para coordenar a inibição e a ativação durante esta etapa do desenvolvimento.

A habilidade de inibir uma resposta dominante se desenvolve no primeiro ano de vida. A forma mais precoce de controle inibitório surge quando a criança deixa de realizar um comportamento prazeroso a partir da solicitação dos cuidadores (Garon, Bryson \& Smith, 2008). No que diz respeito às "tarefas de controle inibitório simples", o paradigma de adiamento da gratificação (delay of gratification paradigm) é o mais utilizado na avaliação controle inibitório no período pré-escolar. Esse paradigma é apresentado de duas formas: através de tarefas onde tipicamente a criança é apresentada a duas recompensas e é orientada a esperar por certo período de tempo para obter as duas, porém pode manifestar a qualquer momento a vontade de obter apenas uma recompensa; ou aquelas onde a criança deve escolher entre alternativas disponíveis (Mischel, 1974). Carlson (2005) encontrou resultados distintos para crianças de diferentes idades no período pré-escolar durante a execução da tarefa de adiamento da gratificação. Enquanto 50\% das crianças com 2 anos de idade foram capazes de aguardar pela segunda recompensa durante 20 segundos, $85 \%$ das crianças com 3 anos de idade conseguiram aguardar por 1 minuto. Essa habilidade parece se desenvolver consideravelmente durante o período pré-escolar, até que aos 4 anos de idade as crianças desse estudo foram capazes de aguardar pela recompensa por 5 minutos (Carlson, 2005).

A literatura sugere que em tarefas do tipo Stroop quanto mais velhas forem as crianças, maior o número de conflitos capazes de serem superados. No teste Stroop os participantes são solicitados a nomear a cor impressa de uma palavra que ao invés de ler a palavra em si. Durante a fase de testagem, a cor impressa da palavra e a palavra são distintas, de forma que os participantes devem inibir a resposta dominante de ler a palavra, para nomear a cor que está impressa. Uma forma simplificada dessa tarefa é o shapes task (Kochanska et al., 1996), onde crianças em idade pré-escolar são apresentadas a imagens de frutas pequenas dentro de frutas maiores (por exemplo, uma maçã pequena 
posicionada dentro da imagem de uma banana maior). A criança deve apontar para a fruta menor, enquanto 0 avaliador as nomeia, inibindo a resposta dominante de apontar para a fruta maior. Crianças com idade entre 2 e 3 anos de idade apresentam um melhor desempenho nesse tipo de tarefa (Carlson, Mandell \& Williams, 2004). Um estudo longitudinal desenvolvido por Hughes's (2007) demonstrou uma melhora no desempenho das crianças dos 2 aos 4 anos de idade em uma tarefa similar: neste caso, na tarefa desenvolvida por Hughes e Ensor (2005), denominada baby Stroop task, as crianças deveriam combinar colheres e tigelas de acordo com seu tamanho (grandes e pequenas) e durante a fase de teste, por eles nomeado de silly game, deveriam emparelhar colheres e tigelas de forma inversa (colheres grandes com tigelas pequenas e tigelas grandes com colheres pequenas). Outra tarefa baseada no paradigma Stroop é a grass-snow task. Nestas tarefas as crianças devem apontar para a cor branca enquanto o avaliador diz grama (grass) e para a cor verde quando o avaliador diz neve (snow). Estudos apontam para uma melhora na performance nesta tarefa, e em outras do tipo Stroop, entre os 3 e 5 anos de idade (Carlson, 2005). O day-night task é outra tarefa baseada no mesmo paradigma. Nesta tarefa o avaliador primeiro se certifica de que a criança compreende que o sol está presente durante o dia e a lua aparece durante a noite. A partir disto orienta a criança que ela deve dizer "noite" sempre que a figura do sol for apresentada e a dizer "dia" sempre que a figura da lua aparecer. Antes de iniciar a fase de testagem, a criança deve responder corretamente por pelo menos 3 vezes, durante as 4 tentativas que compões a fase de ensaio. A fase de testagem compreende uma seqüência de 16 tentativas, onde são apresentados 8 cartões com a imagem do sol e outros $8 \mathrm{com}$ a imagem da lua, apresentados aleatoriamente de forma previamente estabelecida (Aguilar-Pardo et al., 2013). 


\subsubsection{Flexibilidade Cognitiva}

Menos encontradas durante a revisão, as tarefas que recrutam o funcionamento da flexibilidade cognitiva envolvem o deslocamento de um estado mental a outro. Essas tarefas requerem duas etapas: na primeira o participante forma uma ideia, onde é feita uma associação entre um estímulo e uma resposta. A partir disto, o participante é solicitado a focar sua atenção em um estímulo relevante e a ignorar os distratores, a partir disso mantém uma regra a ser seguida, com o apoio da memória de trabalho. Na segunda fase, o participante deve adotar uma nova regra (conflitante com a primeira) para a execução satisfatória da tarefa. Esse tipo de tarefa pode variar de acordo com a quantidade de conflitos que o participante deve superar durante sua realização desenvolvimento (Garon, Bryson \& Smith, 2008).

A distinção entre uma e outra tarefa que se propõe a medir a flexibilidade cognitiva diz respeito a natureza ou ao tipo de substituição a ser utilizado (Nagahama, Fukuyama \& Shibasak, 2002). No que diz respeito ao tipo de tarefa, o deslocamento de uma ideia a outra ocorre a níveis perceptuais ou variam de acordo com a resposta que deve ser apresentada. Tarefas onde há uma mudança na regra que deve ser seguida pelo participante, para selecionar diferentes aspectos do estímulo apresentado, é denominada flexibilidade atencional (attention shifting), enquanto tarefas que envolvem a alteração de regra, incidindo sobre uma resposta motora, são conhecidas como mudança de tarefa/resposta (task/response shifting) (Rushworth, Passingham \& Nobre, 2005). 


\section{Objetivos}

\subsection{Objetivo Geral}

O presente trabalho tem como objetivo a revisão de instrumentos de avaliação neuropsicológica das funções executivas de crianças em idade préescolar (2 a 6 anos incompletos).

\subsection{Objetivos Específicos}

Realizar uma revisão integrativada literatura com o objetivo de identificar os instrumentos disponíveis para avaliação neuropsicológica das funções executivas de pré-escolares, em âmbito nacional e internacional.

Elaborar uma proposta de avaliação destas funções, a partir dos dados obtidos com a revisão, tomando-se em conta a idade e as subcategorias avaliadas: funções executivas (controle inibitório, flexibilidade cognitiva e memória de trabalho). 


\section{Metodologia}

Foi realizada uma revisão integrativa da literatura com o objetivo de identificar quais instrumentos de avaliação neuropsicológica estão disponíveis para se avaliar as funções executivas de crianças em idade pré-escolar, mais especificamente dos 2 aos 6 anos de idade (24 a 72 meses). A partir disso, foram selecionadas algumas tarefas com o objetivo de elaborar um protocolo que avalie tais funções cognitivas.

\section{Revisão Integrativa}

Para a revisão integrativa da literatura as buscas foram realizadas em bases eletrônica de dados, considerando os últimos 10 anos (de 2006 a 2016), com o objetivo de responder a seguinte pergunta: quais são os instrumentos de avaliação neuropsicológica utilizados para avaliar as funções executivas de crianças em idade pré-escolar? A figura 6 descreve as etapas do processo de revisão.

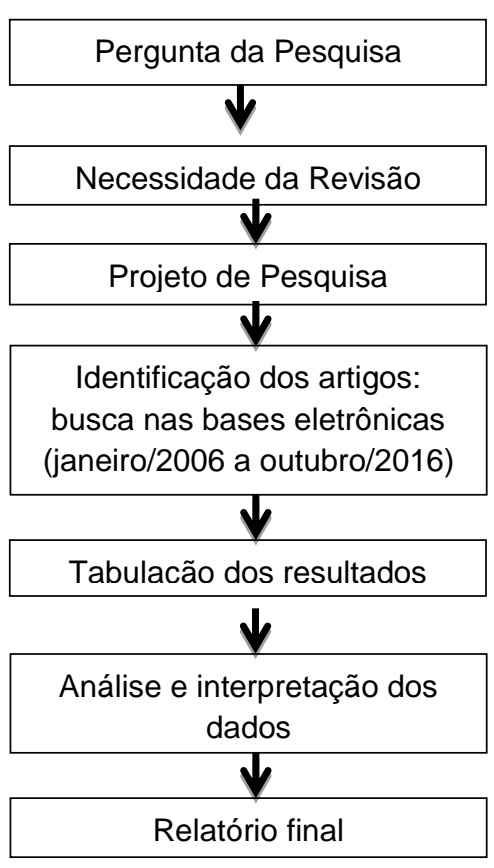

Figura 6. Fluxograma da estratégia de revisão integrativa. 
Como estratégia de refinamento de busca optou-se por incluir apenas estudos experimentais, de avaliação neuropsicológica na primeira infância, com crianças com idade entre 2 e 6 anos incompletos. Os seguintes critérios de inclusão foram adotados para esta revisão: (1) população: crianças em idade pré-escolar; (2) intervenção: instrumentos de avaliação neuropsicológica das funções executivas (não computadorizados); (3) ser artigo original de pesquisa desenvolvida com seres humanos, publicado em periódico indexado nas bases utilizadas, em inglês/ português/ espanhol, durante o período de janeiro de 2006 a outubro de 2016. Monografias, dissertações, teses, resumos, capítulos ou livros e ponto de vista/opinião de especialistas não foram incluídos.

A revisão incluiu publicações indexadas nas bases eletrônicas de dados Web of Science, APA PsycNET, PubMed, Portal CAPES, Lilacs e SciELO, onde foram utilizados os seguintes descritores: (1) População (Preschoolchild\$, Preschoolstudent\$, Childhood, Preschooler\$/ Pré-escolares, Crianças em idade pré-escolar, Crianças/ Pre escolares, Niños em EdadPre-escolar, Niños); (2) Intervenção (ExecutiveFunction $\$$ / Função executiva, Funções executivas/ FunciónEjecutiva, Funciones Ejecutivas).

A tabela foi organizada de acordo com a função avaliada (funções executivas e seus componentes) e também de acordo com a faixa etária: 24 a 72 meses, ou 2 a 6 anos (incompletos). A tabela apresenta a descrição da tarefa a ser realizada, sendo apresentada aquela tarefa que contribuía com uma descrição mais abrangente. Tarefas que não explicitaram o componente das FE a ser avaliado também não foram incluídas. No que diz respeito à organização das tarefas do protocolo por faixa etária, aqueles trabalhos que apresentaram apenas a média da idade da amostra, e não sua faixa etária, tiveram a faixa etária calculada a partir do desvio padrão apresentado. 


\section{Resultados}

O estudo desenvolvido por Allan et al. (2015) se propôs a medir, dentre outros construtos, o controle inibitório e a memória de trabalho em uma amostra de 279 crianças em idade pré-escolar, com idades entre 38 e 65 meses. Para avaliação da memória de trabalho verbal, foram utilizadas as seguintes tarefas: Word Span reversed task, Size Ordering task, Listening Span task. Como medida de controle inibitório, o mesmo estudo utilizou a tarefa Knock/tap (Developmental Neuropsychological Assessment [NEPSY]). Os resultados evidenciaram que o bom conhecimento acerca dos deficit cognitivos e comportamentais, associados à diferentes patologias, depende diretamente do conhecimento sobre os diferentes construtos avaliados. Desta forma, o estudo demonstrou que a atenção e as funções executivas representam diferentes atributos na população avaliada e que esses construtos apresentam diferente impacto no desenvolvimento acadêmico da criança no período pré-escolar.

Astle et al. (2013) realizaram uma pesquisa que buscou investigar quais funções cognitivas estavam associadas à capacidade de representação mental em crianças de 4 anos de idade, numa amostra de crianças de 41 a 61 meses de idade. Para compreender a capacidade representacional destas crianças utilizaram medidas de memória de trabalho verbal e visuoespacial. Com o objetivo de medir a memória de trabalho verbal utilizaram a tarefa Counting and Labeling task, onde as crianças deveriam contar e nomear itens simultaneamente - nesta tarefa a criança deve manipular dois conteúdos verbais independentes ao mesmo tempo, de maneira que comumente crianças aos 3 anos de idade apresentam grande dificuldade na realização da tarefa, enquanto é evidente a melhora do desempenho aos 4 e 5 anos de idade. Como medida de memória de trabalho visuoespacial foi aplicada a tarefa Corsi Span, que representa uma versão adaptada para o público infantil do Blocos de Corsi, teste amplamente utilizado com a população adulta. Esse estudo evidenciou de que maneira a capacidade representacional de crianças em idade pré-escolar está relacionada à atuação da memória de trabalho.

O Word Span task é uma tarefa que se propõe a medir a memória de trabalho verbal. Esta tarefa é baseada no subteste span de dígitos do WISC-III. No estudo realizado por Aarnoudse-Moens et al. (2009) esta medida foi utilizada durante o exame das funções executivas numa amostra de 200 crianças, com 
idades variando entre 4 e 12 anos de idade. O objetivo do estudo foi avaliar estas funções em crianças pré-maturas (idade gestacional < 30 semanas), uma vez que fatores de risco neonatal, além do nível educacional dos cuidadores, teriam impacto direto sobre o desenvolvimento das $\mathrm{FE}$, e de que forma esses dados poderiam variar de acordo com o gênero e a idade dessas crianças. $O$ estudo apontou que o desenvolvimento pós-natal, assim como o nível educacional dos cuidadores, representam fatores preditivos importantes para o desenvolvimento das FE de crianças pré-maturas, mas não necessariamente as complicações neonatais teriam relação direta com tal desenvolvimento. Desta forma, nem o crescimento intra-uterino insuficiente, ou as doenças crônicas provenientes desta condição, não apresentaram relação direta com o desempenho das crianças que participaram do estudo.

O objetivo do estudo transversal realizado por Abubakar et al. (2013) foi realizar a investigação dos estágios iniciais das funções executivas numa população de 319 crianças, com idade entre 6 e 35 meses de idade, onde 17 destas foram expostas, mas não infectadas, pelo vírus da AIDS (HIV) e 31 delas estavam infectadas pelo vírus. A medida utilizada nesse estudo foi uma variação da tarefa $A$-not- $B$. Esta tarefa demanda o aprendizado de um estímulo-resposta, de maneira que a memória de trabalho, o controle inibitório e a flexibilidade cognitiva deverão atuar para o bom desempenho na tarefa. A tarefa $A-n o t-B$ é uma medida bem estabelecida no que diz respeito à avaliação das FE e está evidenciado que o desempenho na tarefa é sensível à maturação do organismo. O padrão dos resultados apontados neste estudo, para aquelas crianças expostas ou contaminadas pelo vírus HIV, sugerem o impacto desta condição, em relação ao grupo controle, de modo que estas crianças foram significativamente menos aptas a completarem a tarefa de maneira satisfatória. As observações clínicas realizadas no estudo apontaram que dificuldades na regulação emocional e a persistência durante a execução da tarefa, podem ter contribuído significativamente para este resultado.

Alguns estudos sugerem que crianças com Síndrome de Down (SD) apresentam prejuízo no desenvolvimento cognitivo e social. No estudo realizado por Amadó et al. (2016) foram avaliadas associações entre a cognição social e diferentes componentes das funções executivas em 30 crianças com SD, com idades entre 4 e 12 anos. As mesmas tarefas utilizadas com este grupo foram administradas em grupos controle, em (1) crianças com a mesma idade cronológica e (2) crianças com o mesmo nível de desenvolvimento lingüístico. 
Dentre as medidas de função executiva, o estudo utilizou a tarefa Frog task , como medida de memória de trabalho visuoespacial (onde duas regras devem ser seguidas, simultaneamente, para o desempenho satisfatório durante a avaliação). Os resultados apontaram que diferentes componentes das funções executivas apresentaram prejuízo, de forma desigual, no grupo experimental. Os participantes com SD mostraram menor alteração no controle inibitório, especialmente quando comparados com o grupo de mesmo nível de desenvolvimento linguístico. Os resultados sugeriram também que crianças com SD apresentam uma melhora no funcionamento social e executivo à medida em que ocorre o desenvolvimento, seja este cronológico ou relacionado às habilidades linguísticas.

Um dos objetivos do estudo transversal desenvolvido por Adams et al. (2015) foi avaliar o processamento sensorial, e sua correlação com o funcionamento executivo, em 127 crianças com idade pré-escolar ( 3 a 5 anos de idade) nascidas prematuras. Dentre as medidas de função executiva foram utilizadas as tarefas Six boxes (memória de trabalho visuoespacial) e Dimensional Change Card Sort (DCCS), como medida de flexibilidade cognitiva. O estudo evidenciou que crianças nascidas pré-maturas apresentam maior prejuízo no processamento sensorial, quando comparadas àquelas do grupo controle, nascida à termo. No grupo experimental foi observada uma correlação entre o prejuízo no processamento sensorial e o desempenho em tarefas que tinham por objetivo medir o controle inibitório, porém, nas tarefas acima mencionadas, não houve diferença estatisticamente significante entre os grupos.

O estudo realizado por Aguilar-Pardo et al. (2013) investigou a relação entre o comportamento altruísta e três medidas de funções executivas (controle inibitório, memória de trabalho e flexibilidade cognitiva) em 72 crianças com idades entre 4 e 6 anos (56 a 79 meses). Como medida de memória de trabalho visuoespacial foi utilizada a tarefa Eight Boxes task. A tarefa Day/Night task foi utilizada para avaliação do controle inibitório destas crianças. Como sugerido pelos autores, foram encontradas associações positivas entre o comportamento altruísta e o controle inibitório em crianças desta faixa etária. No que diz respeito às outras medidas utilizadas no estudo, não foram identificadas relações significativas entre o comportamento altruísta e o desempenho em tarefas de memória de trabalho e flexibilidade cognitiva. 
O controle inibitório é definido como a habilidade necessária para executar um comportamento direcionado, de maneira que respostas dominantes devem ser inibidas para o satisfatório desempenho. No estudo desenvolvido por Allan e Lonigan (2011), tarefas de controle inibitório (hot e cool tasks) foram aplicadas numa amostra de 234 crianças em idade pré-escolar (36 a 71 meses). As tarefas descritas como hot tasks, incluíram box search task, delay of gratification task, gift delay task, less is more taske shapes task. Dentre aquelas descritas como cool tasks, grass-snow task, headto toes taske walk a line slowly task, foram as tarefas utilizadas. Os resultados do estudo apontaram que ainda que o controle inibitório seja relacionado ao desempenho acadêmico e socioemocional, este fator está mais fortemente associado ao desempenho acadêmico. Apartir da revisão realizada foram identificadas tarefas que se propõem a medir as FE de pré-escolares. A tabela 1 apresenta a descrição destas tarefas, agrupadas de acordo com os três componentes previamente descritos: memória de trabalho, controle inibitório e flexibilidade cognitiva. As tarefas foram também agrupadas de acordo com a faixa etária. A tabela 2 apresenta a correção das tarefas descritas na tabela 1 . 


\subsection{Avaliação das Funções Executivas de Pré-escolares}

\begin{tabular}{|c|c|c|c|c|c|}
\hline \multicolumn{2}{|c|}{ Função Avaliada } & Tarefa & Descrição* & $\begin{array}{c}\text { Faixa Etária } \\
\text { (meses) }\end{array}$ & Referência \\
\hline \multirow{4}{*}{\multicolumn{2}{|c|}{$\begin{array}{l}\text { Memória de } \\
\text { Trabalho }\end{array}$}} & $\begin{array}{l}\text { 1. Word span } \\
\text { reversed task }\end{array}$ & $\begin{array}{l}\text { A criança é apresentada a uma lista de palavras conhecidas e é então } \\
\text { solicitada a repetir as palavras em ordem inversa. A lista de palavras } \\
\text { varia de } 2 \text { a } 8 \text { palavras, onde três tentativas são realizados em cada } \\
\text { nível. }\end{array}$ & $\begin{array}{l}38 \text { a } 65 \\
\text { meses }\end{array}$ & Allan et al., 2015 \\
\hline & & $\begin{array}{l}\text { 2. Size ordering } \\
\text { task }\end{array}$ & $\begin{array}{l}\text { É apresenta a criança, oralmente, uma lista de objetos conhecidos (por } \\
\text { exemplo, carro, casa, cachorro) e então é solicitado que esta repita, em } \\
\text { ordem, os objetos menores primeiro, seguidos dos maiores (por } \\
\text { exemplo, cachorro, carro, casa). A lista de objetos varia de } 2 \text { a } 8 \\
\text { palavras em cada nível, com três tentativas, também para cada nível. }\end{array}$ & $\begin{array}{l}38 \text { a } 65 \\
\text { meses }\end{array}$ & Allan et al., 2015 \\
\hline & & $\begin{array}{l}\text { 3. Listening span } \\
\text { task }\end{array}$ & $\begin{array}{l}\text { Nesta tarefa as crianças são solicitadas a responder uma lista de } \\
\text { questões simples, como por exemplo: cachorros latem? Gatos podem } \\
\text { voar? Depois de responder, elas são solicitadas a evocar as últimas } \\
\text { palavras de cada questão. As questões são apresentadas em grupos } \\
\text { de } 2,3 \text { ou } 4 \text {, com três tentativas em cada nível. }\end{array}$ & $\begin{array}{l}38 \text { a } 65 \\
\text { meses }\end{array}$ & Allan et al., 2015 \\
\hline & & $\begin{array}{l}\text { 4. Counting and } \\
\text { Labeling task }\end{array}$ & $\begin{array}{l}\text { A criança é solicitada a contar e nomear itens simultaneamente. Esta } \\
\text { tarefa requer que a criança seja capaz de armazenar dois estímulos } \\
\text { verbais independentes ao mesmo tempo. } \\
\text { No primeiro momento, o avaliador demonstra nomeando três itens (por } \\
\text { exemplo, árvore, presente e vaca), então os conta (um, dois, três) e por } \\
\text { fim conta e nomeia simultaneamente: "um é a árvore", "dois é o } \\
\text { presente" e "três é a vaca". A partir disto, a criança executa estes três } \\
\text { níveis por duas tentativas, cada uma usando um novo material. }\end{array}$ & $\begin{array}{l}47 \text { a } 61 \\
\text { meses }\end{array}$ & Astle et al., 2013 \\
\hline
\end{tabular}




\begin{tabular}{|c|c|c|c|c|c|}
\hline & & 5. Word Span task & $\begin{array}{l}\text { Baseado no subtestespan de dígitos do WISC-III, nesta tarefa o } \\
\text { avaliador apresenta a criança uma lista de palavras (faladas) e a } \\
\text { criança é solicitada a repetir as palavras que foram ditas. Assim como } \\
\text { no subteste do WISC-III, o número de palavras aumenta de um nível } \\
\text { para outro, chegando a no máximo } 6 \text { palavras. Existem duas seqüência } \\
\text { de palavras em cada nível, onde a criança deve reproduzir ao menos } \\
\text { uma seqüência para avançar para o nível seguinte. } \\
\text { Na fase de "ordem direta" da tarefa, as crianças devem reproduzir as } \\
\text { palavras na ordem dita pelo avaliador. Na fase de "ordem inversa", as } \\
\text { palavras devem ser repetidas inversamente a ordem apresentada pelo } \\
\text { avaliador. }\end{array}$ & $\begin{array}{c}60 \text { a } 72 \\
\text { meses }\end{array}$ & $\begin{array}{l}\text { Aarnoudse-Moens } \\
\text { et al., } 2009\end{array}$ \\
\hline \multirow[b]{2}{*}{$\begin{array}{l}\text { Memória de } \\
\text { Trabalho }\end{array}$} & \multirow[b]{2}{*}{ Visuoespacial } & 6. A-Not-B task & $\begin{array}{l}\text { A criança é solicitada à identificar o local onde será escondido um } \\
\text { objeto de seu interesse. O objeto é escondido enquanto a criança } \\
\text { observa, em um de dois locais possíveis (locais } A \text { e B), e a opção de } \\
\text { escolha é reapresentada a criança depois de um breve período de } \\
\text { tempo. O local escolhido para esconder o objeto é alternado de uma } \\
\text { seqüência a outra. } \\
\text { Durante a tarefa deve-se observar o erro de perseveração, onde a } \\
\text { criança continua por buscar o objeto no local onde pôde recuperá-lo, } \\
\text { ao invés de observar que este foi escondido em um novo local. }\end{array}$ & $\begin{array}{l}\text { A partir dos } 6 \\
\text { meses }\end{array}$ & $\begin{array}{c}\text { Abubakar et al., } \\
2013\end{array}$ \\
\hline & & 7. FrogTask & $\begin{array}{l}\text { Esta tarefa apresenta um total de } 8 \text { tentativas (e } 2 \text { ensaios) divididas } \\
\text { em } 4 \text { níveis de dificuldade, onde a criança deverá seguir duas regras } \\
\text { simultaneamente. } \\
\text { Durante a execução da tarefa, um sapo é posicionado sobre quadrados } \\
\text { de um tabuleiro. O sapo "pula" de um quadrado a outro. A criança deve } \\
\text { apontar o quadrado de ponto de partida do sapo (primeira regra) e é } \\
\text { orientada a bater na mesa com uma das mãos sempre que o sapo } \\
\text { "saltar" para um novo quadrado (segunda regra). }\end{array}$ & $\begin{array}{l}\text { A partir dos } \\
33 \text { meses }\end{array}$ & $\begin{array}{l}\text { Amadó et al., } \\
2016\end{array}$ \\
\hline
\end{tabular}


São apresentadas às crianças uma bandeja contendo 6 caixas, onde cada caixa contém um objeto e é então fechada. E solicitado a criança que encontre cada um dos objetos das caixas, um de cada vez. Entre cada uma das vezes que a criança procura pelo objeto, a bandeja é retirada do alcance da criança por 5 segundos. A criança pode usar 8. Six boxes task como pista a posição da caixa, ou a cor da tampa da caixa, para recordar quais foram as caixas já observadas.

36 a 60

meses

Adams et al.,

Durante a fase de treino, que ocorre antes da execução da tarefa propriamente dita, 3 caixas são apresentadas, de maneira que a criança compreenda a regra que deve ser seguida durante a fase de avaliação.

Esta tarefa é uma adaptação do teste blocos de Corsi, para a população infantil.

$\mathrm{O}$ avaliador apresenta a criança um quadro com blocos em formato de flor, idênticos. A criança é então orientada a "fazer de conta" que seu dedo é um sapo que deve saltar de uma flor a outra. É dito a criança que observe com atenção quais flores o sapo do avaliador (dedo) toca e é então solicitada a tocar as mesmas flores, na mesma ordem.

O número de flores que são tocadas aumenta em 1 a cada duas tentativas, passando para o nível seguinte, até que a criança não seja mais capaz de reproduzir duas tentativas de um mesmo nível.
47 a 61

meses

Astle et al., 2013

A criança é inicialmente apresentada à um conjunto de 8 caixas, com diferentes padrões e cores. Então, o avaliador coloca um adesivo em uma das caixas e solicita a criança que se recorde em que caixa adesivo foi fixado. Enquanto não está atenta, as caixas são então

10. Eight boxes task misturadas. Dez segundos depois a criança é solicitada a encontrar a caixa correta. $\mathrm{O}$ avaliador então repete cada uma das caixas, seguindo uma ordem aleatória pré-estabelecida. O padrão de cada fileira onde estão posicionadas as caixas também é estabelecido previamente. Ou seja, após cada movimentação a posição ocupada pelas caixas será a mesma. 
A criança é solicitada a apontar para o bloco verde quando o avaliador

11. Grass-Snow

task

\section{Head to toes}

task

slowly task diz "neve" e a apontar para o bloco branco quando o avaliador diz "grama". São administradas duas tentativas até que a criança compreenda as regras do jogo e 16 seqüência na fase de teste.
36 a 71

meses

Allan e Lonigan,

2011

A criança é orientada a fazer o oposto do que diz o avaliador. Quando avaliador diz para a criança tocar os dedos dos pés, ela deve tocar a cabeça, e vice versa.

36 a 71

meses

Allan e Lonigan 2011

Uma fita azul, medindo $6,35 \mathrm{~cm} \times 3,66 \mathrm{~mm}$, é posicionada em linha reta no chão. A criança é primeiramente instruída a anda normalmente, de uma pontaa outra da fita. A partir disto, por duas tentativas, a crianças

36 a 71

meses

Allan e Lonigan, é instruída a caminhar sobre a fita o mais lentamente possível.
Controle Inibitório

CoolTasks

14. Knock/tap (Developmental

Neuropsychological

Assessment

[NEPSY]
Durante 6 tentativas de ensaio as crianças são orientadas a imitar os gestos realizados com as mãos pelo avaliador, batendo na mesa por vezes com a mão fechada, em outras com a palma da mão. Depois que a resposta dominante (imitação) é estabelecida, as crianças são então orientadas à fazer o oposto daquilo que faz o avaliador (bater com a palma da mão enquanto o orientador bate com a mão fechada $e$ vice versa). O teste é composto por 12 tentativas.

avaliador primeiro se certifica de que a crianca compreende que sol está presente durante o dia e a lua aparece durante a noite. A partir disto orienta a criança que ela deve dizer "noite" sempre que a figura do sol for apresentada e a dizer "dia" sempre que a figura da lua aparecer.

15. Day/Night task Antes de iniciar a fase de testagem, a criança deve responder corretamente por pelo menos 3 vezes, durante as 4 tentativas que compões a fase de ensaio. A fase de testagem compreende uma seqüência de 16 tentativas, onde são apresentados 8 cartões com a imagem do sol e outros $8 \mathrm{com}$ a imagem da lua, apresentados aleatoriamente de forma previamente estabelecida.
38 a 65

meses

Allan et al., 2015

56 a 79

meses

Aguilar-Pardo et al., 2013 


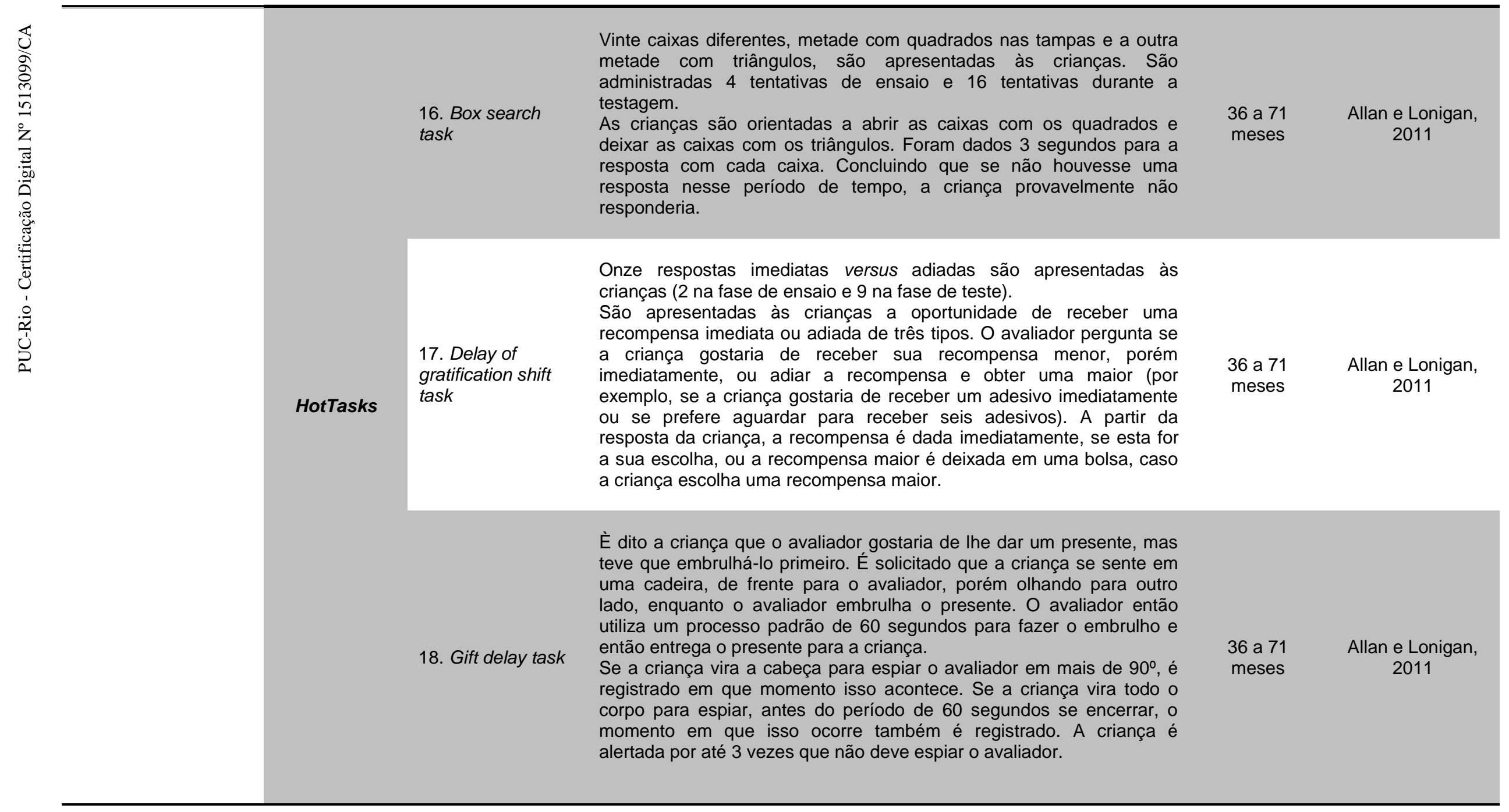




\begin{tabular}{|c|c|c|c|c|}
\hline & $\begin{array}{l}\text { 19. Less is more } \\
\text { task }\end{array}$ & $\begin{array}{l}\text { Adesivos são posicionados em doismontes, à direita e à esquerda da } \\
\text { criança, onde um monte tem } 5 \text { adesivos e a outra tem } 2 \text {. É questionado } \\
\text { a criança qual dos dois montes ela prefere (normalmente ela irá } \\
\text { responder que prefere o monte com mais adesivos). Após ser } \\
\text { orientada que o objetivo do jogo é que a criança obtenha o maior } \\
\text { número possível de adesivos, é apresentado a ela o "urso guloso" que } \\
\text { quer todos os adesivos para ele. O avaliador explica para a criança que } \\
\text { sempre que ela for questionada sobre qual monte ela gostaria de obter, } \\
\text { aquele que ela apontar será dado ao "urso guloso", e o outro será dela. } \\
\text { É administrada uma tentativa de ensaio e } 16 \text { tentativas durante a fase } \\
\text { de testagem, onde metade dessas tentativas tem o monte de } 5 \\
\text { adesivos posicionado do lado esquerdo da criança. }\end{array}$ & $\begin{array}{l}36 \text { a } 71 \\
\text { meses }\end{array}$ & $\begin{array}{c}\text { Allan e Lonigan, } \\
2011\end{array}$ \\
\hline & 20. Shapes task & $\begin{array}{l}\mathrm{Na} \text { primeira fase do teste a criança é orientada de que serão } \\
\text { apresentadas figuras, onde frutas pequenas estão posicionadas dentro } \\
\text { de frutas maiores e que elas devem nomear as frutas menores. } \\
\text { São } 12 \text { tentativas nesta fase de teste, contendo as mesmas frutas, } \\
\text { onde metade das figuras são congruentes (frutas grandes e pequenas } \\
\text { são as mesmas) e a outra metade são incongruentes. As crianças } \\
\text { recebem } 12 \text { recompensas antes de se iniciar o teste e são informadas } \\
\text { que perdem uma recompensa por erro executado. } \\
\text { Após essas } 12 \text { tentativas iniciais, duas outras frutas são adicionadas a } \\
\text { tarefa. Outras } 16 \text { tentativas são administradas, onde novamente } \\
\text { metade das figuras é congruente e a outra metade incongruente, e são } \\
\text { orientadas novamente a nomear as figuras menores. }\end{array}$ & $\begin{array}{l}38 \text { a } 75 \\
\text { meses }\end{array}$ & $\begin{array}{c}\text { Allan e Lonigan, } \\
2014\end{array}$ \\
\hline $\begin{array}{l}\text { Flexibilidade } \\
\text { Cognitiva }\end{array}$ & 21. A-Not-B & $\begin{array}{l}\text { A criança é solicitada a identificar o local onde será escondido um } \\
\text { objeto de seu interesse. O objeto é escondido enquanto a criança } \\
\text { observa, em um de dois locais possíveis (locais A e B), e a opção de } \\
\text { escolha é reapresentada a criança depois de um breve período de } \\
\text { tempo. O local escolhido para esconder o objeto é alternado de uma } \\
\text { sequência a outra. } \\
\text { Durante a tarefa deve-se observar o erro de perseveração, onde a } \\
\text { criança continua por buscar o objeto no local onde pôde recuperá-lo, } \\
\text { ao invés de observar que este foi escondido em um novo local. }\end{array}$ & $\begin{array}{l}\text { A partir dos } 6 \\
\text { meses }\end{array}$ & $\begin{array}{c}\text { Abubakar et al., } \\
2013\end{array}$ \\
\hline
\end{tabular}


22. Dimensional A criança é apresentada a cartas contendo cores e formas distintas, Change Card Sort que podem ser agrupadas de acordo com duas regras (cor ou forma). (DCCS) A criança primeiro é instruída a agrupar as
regra e depois de acordo com a segunda.

Os participantes escolhem algumas cartas a partir de um baralho. Em cada carta do baralho aparece a figura de um animal impresso em cores vivas vestindo uma peça de roupa. Duas destas três características (tipo de animal e cor) correspondem a duas dimensões de classificação. Cada dimensão de classificação contém 4 níveis: 4 cores (vermelho, verde, azul e amarelo) e 4 animais (vaca, porco, leão e lobo).

Cada carta contém um nível de cada dimensão, por exemplo, uma carta apresenta a figura de um lobo vermelho usando um chapéu, o que representa um nível de cada uma das dimensões de classificação.

O baralho é composto por uma carta para cada combinação única dos níveis possíveis, formando um total de 64 cartas.

23. Versão modificada do

O baralho é previamente organizado antes de cada tentativa, onde uma tentativa corresponde a um conjunto de 30 agrupamentos das cartas.

Sort

Os participantes são orientados a pegar as cartas que estão voltadas com a face para a mesa, de maneira que inicialmente a figura não pode ser vista, e a agrupá-las em um dos quatro montes, baseados em uma das dimensões descritas previamente.

Cada monte contém uma "carta guia" que serve de exemplo para o agrupamento das cartas seguintes, de maneira que cada nível, de cada regra estão representadas por essas cartas. Por exemplo, uma "carta guia" apresenta a figura de um leão verde usando óculos. Esta é a única "carta guia" que contém essas três características, de maneira que os participantes devem agrupar neste monte cartas com animais verdes, ou aquelas onde aparece um leão, a depender da regra que está sendo seguida.

A partir de cada agrupamento das cartas o avaliador diz se as cartas foram agrupadas corretamente ou não, de acordo com a regra que está sendo seguida naquela tentativa.

36 a 60

meses 2014

Os participantes são orientados a escolher 30 cartas por tentativa. 
Ainda que o avaliador diga quando a carta foi corretamente posicionada, este não revela qual é a regra que está sendo seguida em cada tentativa. Assim como acontece no Wisconsin Card Sort Test, a regra é alterada sempre que 15 cartas são agrupadas (ou seja, no meio de cada tentativa). Assim como no início, os participantes não são informados de que a regra foi alterada, de forma que o participante somente terá noção de que isso ocorreu através do feedback dado pelo avaliador. A regra é alternada de acordo com a cor ou de acordo com o animal e vice versa.

24. Versão modificada do

Object

Classification Task for Children (OCTC)
No teste original Object Classification Task for Children (OCTC), a criança é solicitada a agrupar 6 brinquedos de acordo com três regras pré-determinadas: por cor (vermelho ou amarelo), por tamanho (grande ou pequeno) e por função (carro ou avião).

Nesta forma modificada do teste, são utilizadas cartas no lugar de brinquedos. Estas cartas contêm carros e aviões vermelhos ou amarelos, e podem ser agrupadas de acordo com as regras do teste original.

Existem três condições caracterizadas por três níveis de dificuldade de estrutura no que diz respeito à ajuda oferecida pelo avaliador: (1) geração livre, onde a criança é solicitada a agrupar as cartas sem qualquer ajuda do avaliador, (2) identificação, onde o avaliador elege a categoria e a criança é solicitada a identificá-la, e (3) pista explícita onde a criança é explicitamente orientada a agrupar as cartas de determinada forma.

Primeiramente são realizados 2 ensaios, onde a criança é solicitada a agrupar 4 cartas com diferentes figuras de animais (2 pares de cartas do mesmo animal). A criança é então orientada a agrupar um par do seu lado da mesa e a posicionar o outro par do lado oposto da mesa. Essa fase de teste é importante para identificar se a criança é capaz de agrupar os pares de acordo com a sua aparência.

A partir das tentativas de ensaio, na fase de testagem a criança é apresentada a 6 cartas. Diferentemente da fase de ensaio, estascartas não mostram imagens idênticas para serem agrupadas, em vez disso as crianças são orientadas a agrupar as cartas de acordo com:(1) as cores das figuras ( 3 cartas mostram figuras vermelhas, as outras 3 
imagens pequenas, as outras 3 imagens grandes); e (3) de acordo com a função ( 3 cartas contém a imagem de um carro, as outras 3 de um avião).

Então é dito à criança: "existe algo de similar entre essas imagens"; solicitando após que ela agrupe as cartas de acordo com suas semelhanças de um ou de outro lado da mesa. A partir de um agrupamento correto, de um total de três (ou seja, cor, tamanho ou função), a criança encorajada a nomear a classificação de cada grupo:

"Por que você agrupou estas cartas aqui e as outras ali? O que há de semelhante entre essas figuras?". A resposta da criança é registrada e o avaliador então mistura as cartas e solicita a criança que seja feito um novo tipo de agrupamento: "Agora você irá separar as cartas novamente em dois grupos, porém as semelhanças entre as cartas

devem ser diferentes daquelas utilizadas anteriormente". Este procedimento é repetido até que a criança corretamente agrupe as cartas de acordo com as três classificações possíveis.

Tabela 1. Avaliação das Funções Executivas de Pré-escolares

* Tradução nossa. 
1. Word span reversed task
O número total de tentativas nas quais todas as palavras foram repetidas na ordem correta é registrado (pontuação máxima $=21$ ).

\section{Size ordering} task
A variável dependente é o número total de tentativas nas quais todas as palavras foram repetidas na ordem correta (pontuação máxima possível = 21).

\section{Listening span task}

A variável dependente é o número total de tentativas nas quais pelo menos uma palavra foi evocada corretamente de uma frase que não a última (pontuação máxima possível $=12$ ).

\section{Counting and Labeling task A pontuação é feita a partir da capacidade do participante de contar e nomear ao mesmo tempo, sendo dado 1 ponto para cada resposta correta (pontuação máxima possível $=2$ ).}

5. Word Spantask

A variável dependente é o número total de seqüência evocadas corretamente nas ordens direta e inversa. A ordem inversa é um índice de memória de trabalho.

As variáveis dependentes são: (i) tentativas totais corretas (a soma de todos as tentativas em que a criança selecionou a localização correta); (ii) erros de

6. A-Not-B task perseverarão (o número total de erros cometidos após o primeiro conjunto de duas tentativas resolvidas corretamente); (iii) execução de erros máximos (maior seqüência de erros).

7. Frog Task

Cada teste recebe apenas um ponto se o participante completar o jogo com sucesso (pontuação máxima $=8$ ).

8. Six boxes task A variável dependente é o número de tentativas que a criança precisa para recolher todos os objetos. Pontuações mais altas indicam um desempenho pior.

\section{Corsi Span task}

10. Eight boxes 8).
A pontuação é calculada com base em um valor de 0,5 para cada tentativa correta. A pontuação máxima é de 5 para 10 tentativas.

$$
\text { task }
$$

pontuação é calculada a partir do número de tentativas corretas (de um total de

Nenhum ponto é dado se a criança não apontar; 1 ponto é dado se a criança apontar incorretamente; 2 pontos são dados se a criança se corrigir

11. Grass-Snow automaticamente apontando primeiro para o bloco errado e, sem ajuda do task experimentador, apontando imediatamente apos para o bloco correto; e 3 pontos são dados se a criança apontar apenas para o bloco correto.

\section{Head to toes} task

\section{Walk a line} slowly task
Para cada tentativa, 2 pontos são dados se a criança responder corretamente; 1 ponto é dado para uma tentativa auto-corrigida; e 0 pontos são dados para uma resposta incorreta. 
14.Knock/tap

(Developmental Respostas em um total de 12 tentativas são pontuadas 0-2 (0 para uma resposta Neuropsychological incorreta, 1 para auto-correção e 2 para uma resposta correta).

Assessment

[NEPSY]

15. Day/Night task A pontuação é o número de tentativas corretas (de um total de 16).

16. Box search task Cada caixa é pontuada como acerto/erro, sendo 1 ponto dado se a criança abrir a caixa correta ou mantiver fechada a caixa incorreta.

17. Delay of

gratification shift 1 ponto é dado por cada escolha adiada.

task

18. Less is more 1 ponto é dado cada vez que a criança aponta para a pilha de adesivo correta (a task menor).

19. Shapes task 1 ponto é dado para cada resposta correta e 0 pontos para cada resposta incorreta.

As variáveis dependentes são: (i) tentativas corretas totais (a soma de todas as tentativas em que a criança seleciona a localização correta); (ii) erros de

20. A-Not-B perseverarão (o número total de erros cometidos após o primeiro conjunto de duas tentativas resolvidas corretamente); (iii) execução de erros máximos (maior seqüência de erros).

\section{Dimensional Change Card Sort (DCCS)}

22. Versão modificadado Object Classification Task for Children (OCTC)
A variável dependente é o número de respostas corretas ao classificar de acordo com a segunda dimensão.

22. Versão
modificadado
Object
Classification Task
for Children (OCTC)

Para cada agrupamento correto, a criança recebe 3 pontos. Além disso, um ponto é dado para cada agrupamento nomeado corretamente verbalmente. A pontuação máxima é 12 pontos. Se a criança organizar as cartas corretamente de acordo com a cor, o tamanho ou a função, mas não conseguir ordenar as cartas uma segunda (ou terceira) vez, o examinador ordena as cartas de acordo com uma das categorias restantes. A criança então é solicitada a identificar o agrupamento. Isso é chamado de condição de identificação. Se a criança responder corretamente, uma pontuação de 2 pontos é dada. Se a criança não conseguir identificar, o examinador solicita especificamente à criança que classifique as cartas de acordo com um agrupamento específico. Isso é chamado de condição de dica explícita, onde a criança recebe um ponto para cada agrupamento correto. No entanto, se a criança não entende as instruções da tarefa quando os seis cartões são apresentados, uma dimensão é removida, e a criança recebe quatro cartas, que podem ser ordenadas de acordo com a cor ou o tamanho. O escore bruto total é calculado pela soma de todos os pontos obtidos e é usado como indicativo da habilidade das crianças de alternar entre os conceitos.

Tabela 2. Correção do Protocolo de Avaliação das Funções Executivas de Pré-escolares 


\section{Discussão}

No que diz respeito ao estudo do desenvolvimento das funções executivas, um desafio é a adaptação de tarefas, comumente usadas em estudos com adultos, para crianças pequenas. A escolha de uma estrutura conceitual é fundamental tanto para a adaptação dessas medidas para populações mais jovens, quanto para elaboração de novas tarefas (Garon, Bryson \& Smith, 2008). Duas abordagens se destacam historicamente no que diz respeito à estrutura conceitual utilizada no estudo do desenvolvimento das FE: a primeira entende as FE como um construto único, composto por subprocessos (Shallice, 1988). Nesse sentido, a literatura aponta evidências acerca da perspectiva unitária das FE - por um lado, estudos apontam que diferentes medidas das FE são fortemente correlacionadas, sugerindo um processo comum a estas funções (Miyake et al., 2000); a segunda abordagem teórica enfatiza os diferentes processos, ou componentes, das FE, onde os estudos costumam utilizar a análise fatorial para especificar cada componente das FE (Pennington, 1997). Achados referentes a estes trabalhos apontam que o desempenho em diferentes tarefas propostas para medir as FE são independentes e se utilizam de diferentes estruturas cerebrais (Collette et al., 2005). Alguns pesquisadores adotaram esta abordagem baseados em estudos acerca do funcionamento de redes pré-frontais (Casey, Durston, \& Fossella, 2001), onde estudos na área de neuropsicologia com indivíduos portadores de lesão no córtex pré-frontal demonstraram desempenho diferente em tarefas de FE, apontando para a ativação diferente áreas frontais (Brookshire, Levin, Song, \& Zhang, 2004).

As FE são associadas ao córtex pré-frontal, uma das áreas cerebrais com desenvolvimento mais lento durante o curso da vida (Benes, 2001). Estudos apontam que as funções mais relevantes desempenhadas pelo funcionamento do córtex pré-frontal compreendem a percepção, o pensamento e o controle do comportamento, através da ativação e da inibição de outras áreas cerebrais (Shallice, 2002). Durante o período pré-escolar, componentes fundamentais das funções executivas se desenvolvem, formando a base para o desenvolvimento de processos cognitivos mais complexos até a idade adulta (Garon, Bryson \& Smith, 2008).

A segunda abordagem teórica enfatiza os diferentes processos das FE, onde os estudos costumam utilizar o fator de análise para especificar cada 
componente das FE (Pennington, 1997). Achados referentes a estes trabalhos apontam que o desempenho em diferentes tarefas propostas para medir as FE são independentes e se utilizam de diferentes domínios funcionais (Collette et al., 2005). Alguns pesquisadores adotaram esta abordagem com base em estudos acerca do funcionamento de redes pré-frontais (Casey, Durston, \& Fossella, 2001). Estudos na área de neuropsicologia com indivíduos com lesão no córtex pré-frontal apontaram para diferentes desempenhos em tarefas de FE, apontando para a ativação diferente áreas frontais (Brookshire, Levin, Song, \& Zhang, 2004).

Miyake et al. (2000) argumentaram que parte da dificuldade em estudar componentes das FE é o fato de estas não serem puras. Ao analisar a literatura acerca destas funções, os autores identificaram que os componentes mais comumente citados são a memória de trabalho (working memory), o controle inibitório (reponse inhibition) e a flexibilidade cognitiva (set shifting). Ainda de acordo com os autores, um modelo ideal das FE seria aquele onde seus componentes são parcialmente independentes, porém, correlacionados entre si. Este modelo seria mais coerente que aqueles apresentados anteriormente. Lehto et al. (2003) utilizaram esse modelo num estudo com crianças entre 8 e 13 anos de idade, onde as medidas das FE foram agrupadas de acordo com estes três componentes: flexibilidade cognitiva, memória de trabalho e o controle inibitório. Uma análise fatorial confirmatória indicou que esse modelo melhor se aplica ao estudo das FE, onde os componentes destas funções são parcialmente independentes e correlacionáveis. Em outro estudo de análise fatorial confirmatória do modelo proposto por Miyake et al. (2000) identificaram evidências acerca da dissociação dos componentes das FE, bem como de sua correlação. O modelo proposto por Miyake et al. (2000), oferece uma alternativa para integrar as abordagens desenvolvimentistas acerca das FE.

Zelazo, Qu e Müller (2005) propuseram que durante o período préescolar a representação de uma regra, ou uma informação, se dá de forma hierárquica. Desta maneira, a perseveração ocorre nessa etapa da vida em função de a criança não possuir uma forma integrada de regras incompatíveis, resultando na discrepância entre o que se sabe e o que se faz. Já no final do período pré-escolar as crianças se tornam mais hábeis em refletir sobre regras, integrando os elementos conflituosos de um aprendizado num sistema mais complexo de regras. 
De acordo com Diamond (2006), os componentes das funções executivas, aqui representados por memória de trabalho, controle inibitório e flexibilidade cognitiva, seguem trajetórias próprias de desenvolvimento. Esta autora enfatiza que a dificuldade em superar o conflito trazido por diferentes regras, ou a representação destas, é a causa da perseveração comumente observada durante a avaliação de crianças pequenas. Descreve ainda as FE como a habilidade de superar o comportamento automático e prepotente, suprimindo a experiência prévia (Diamond, 2001). Ou seja, a habilidade para administrar um conflito, durante o processamento de uma informação, é considerado um ponto crítico durante o desenvolvimento das FE no período préescolar. 


\section{Considerações Finais}

A avaliação neuropsicológica de crianças em idade pré-escolar ainda é um tema pouco investigado, quando comparado aos estudos da área com populações de outras faixas etárias. Existe um número limitado, na literatura nacional, de instrumentos que se propõem a medir as funções executivas durante esta etapa do desenvolvimento infantil. A partir desta constatação, o presente estudo se propôs a desenvolver uma ferramenta alternativa que sirva de instrumento para a investigação destas funções ainda na primeira infância, período em que estas estão em plena emergência.

Durante o período de revisão da literatura, para este trabalho, foram selecionados artigos que apresentassem com objetivo medir as funções executivas de crianças em idade pré-escolar, através de instrumentos padronizados, ou de paradigmas classicamente utilizados para o estudo destas funções. As medidas utilizadas nos estudos selecionados se mostraram suficientes para este propósito, apresentando também uma boa descrição das tarefas propostas para avaliação. As tarefas analisadas são importantes, pois, diante da escassez de instrumentos padronizados, estas representam uma alternativa para a avaliação neuropsicológica infantil.

O presente estudo apresenta limitações importantes. A primeira delas diz respeito às funções cognitivas subjacentes às funções executivas. A literatura encontrada, voltada para a avaliação da população pré-escolar se restringe, em sua grande maioria, à avaliação da memória de trabalho, do controle inibitório e da flexibilidade cognitiva. Desta forma, outras funções amplamente estudadas pela Neuropsicologia, com indivíduos em outros períodos do desenvolvimento humano, não são muito investigadas nos estudos que se dedicam à primeira infância. Também deve-se ressaltar que esforços no sentido de adaptação de tarefas, utilizadas na avaliação neuropsicológica de indivíduos adultos e idosos, seria de grande relevância para o estudo do desenvolvimento infantil.

Estudos adicionais sãonecessários para se compreender de forma mais detalhada a emergência das funções executivas no período pré-escolar, bem como de que maneira essa população poderia se beneficiar de intervenções nesta etapa do desenvolvimento. Protocolos que visem à adaptação, para o público infantil, de tarefas amplamente utilizadas na avaliação neuropsicológica, devem ser desenvolvidos para uma maior compreensão do processo de 
desenvolvimento neuropsicológico nos estágios iniciais da vida. Este trabalho é apenas um primeiro passo na direçãoda tentativa de construção de um protocolo que avalie o desenvolvimento das funções cognitivas e de que maneira a compreensão deste desenvolvimento pode oferecer recursos para possíveis demandas acadêmicas e/ou comportamentais. A partir deste primeiro levantamento, novos estudos podem seguir os esforços para o desenvolvimento de outras formas de avaliação da primeira infância. 


\section{Referências bibliográficas}

AARNOUDSE-MOENS, Cornelieke Sandrine Hanan et al. Meta-analysis of neurobehavioral outcomes in very preterm and/or very low birth weight children. Pediatrics, v. 124, n. 2, p. 717-728, 2009.

ABUBAKAR, $A$. et al. The performance of children prenatally exposed to HIV on the A-not-B task in Kilifi, Kenya: a preliminary study. Int $\mathbf{J}$ Environ Res Public Health, v. 10, n. 9, p. 4132-42, Sep 042013.

ADAMS, J. N. et al. Sensory processing in preterm preschoolers and its association with executive function. Early Human Development, v. 91, n. 3, p. 227-233, Mar 2015.

AGUILAR-PARDO, David; MARTÍNEZ-ARIAS, Rosario; COLMENARES, Fernando. The role of inhibition in young children's altruistic behaviour. Cognitive Processing, v. 14, n. 3, p. 301-307, 2013.

ALCHIERI, João Carlos; MADRUGA, Beatriz M. Instrumentos de avaliação neuropsicológica em uso no Brasil: lacunas e demandas para a pesquisa. Revista Especialize On-line IPOG, 008(1), 2014.

ALLAN, D. M. et al. Identifying unique components of preschool children's selfregulatory skills using executive function tasks and continuous performance tests. Early Childhood Research Quarterly, v. 32, p. 40-50, 2015.

ALLAN, N. P.; LONIGAN, C. J. Examining the dimensionality of effortful control in preschool children and its relation to academic and socioemotional indicators. Dev Psychol, v. 47, n. 4, p. 905-15, Jul 2011.

ALLOWAY, Tracy Packiam et al. A structural analysis of working memory and related cognitive skills in young children. Journal of experimental child psychology, v. 87, n. 2, p. 85-106, 2004.

AMADÓ, Anna; SERRAT, Elisabet; VALLÈS-MAJORAL, Eduard. The role of executive functions in social cognition among children with Down syndrome: relationship patterns. Frontiers in psychology, v. 7, p. 1363, 2016.

ANASTAS, J. R.; KELTY-STEPHEN, D. G.; DIXON, J. A. Executive Function as an Interaction-Dominant Process. Ecological Psychology, v. 26, n. 4, p. 262282, Oct 2014.

ANDERSON, Peter. Assessment and development of executive function (EF) during childhood. Child neuropsychology, v. 8, n. 2, p. 71-82, 2002.

ANDERSON, Vicki; NORTHAM, Elisabeth; WRENNALL, Jacquie. Developmental neuropsychology: A clinical approach. Psychology Press, 2014.

ASTLE, A. et al. When this means that: the role of working memory and inhibitory control in children's understanding of representations. J Exp Child Psychol, v. 116, n. 2, p. 169-85, Oct 2013.

BADDELEY, Alan. Working memory, thought, and action. OUP Oxford, 2007. 
BADDELEY, Alan. Fractionating the central executive. Principles of frontal lobe function, p. 246-260, 2002.

BADDELEY, Alan. The episodic buffer: a new component of working memory?. Trends in cognitive sciences, v. 4, n. 11, p. 417-423, 2000.

BARKLEY, Russell A. Behavioral inhibition, sustained attention, and executive functions: constructing a unifying theory of ADHD. Psychological bulletin, $v$. 121, n. 1, p. 65, 1997.

BARKLEY, Russell A. The executive functions and self-regulation: An evolutionary neuropsychological perspective. Neuropsychology review, v. 11, n. 1, p. 1-29, 2001.

BARROS, Priscila Magalhães; HAZIN, Izabel. Avaliação das funções executivas na infância: revisão dos conceitos e instrumentos. Psicologia em Pesquisa, v. 7, n. 1, p. 13-22, 2013.

BELL, Martha Ann. Brain electrical activity associated with cognitive processing during a looking version of the A-not-B task. Infancy, v. 2, n. 3, p. 311-330, 2001.

BELL, Martha Ann; FOX, Nathan A. The relations between frontal brain electrical activity and cognitive development during infancy. Child development, v. 63, n. 5, p. 1142-1163, 1992.

BELL, Martha Ann; FOX, Nathan A. Individual differences in object permanence performance at 8 months: Locomotor experience and brain electrical activity. Developmental Psychobiology, v. 31, n. 4, p. 287-297, 1997.

BENES, FRANCINE M. The development of prefrontal cortex: The maturation of neurotransmitter systems and their interactions. Handbook of developmental cognitive neuroscience, v. 2, p. 79-92, 2001.

BROOKSHIRE, Bonnie et al. Components of executive function in typically developing and head-injured children. Developmental neuropsychology, v. 25, n. 1-2, p. 61-83, 2004.

BURGESS, Paul W.; SIMONS, Jon S. 18 Theories of frontal lobe executive function: clinical applications. The effectiveness of rehabilitation for cognitive deficits, p. 211, 2005.

CARLSON, Stephanie M. Developmentally sensitive measures of executive function in preschool children. Developmental neuropsychology, v. 28, n. 2, p. 595-616, 2005.

CARLSON, Stephanie M.; MANDELL, Dorothy J.; WILLIAMS, Luke. Executive function and theory of mind: stability and prediction from ages 2 to 3. Developmental psychology, v. 40, n. 6, p. 1105, 2004.

CASEY, B. J.; DURSTON, Sarah; FOSSELLA, John A. Evidence for a mechanistic model of cognitive control. Clinical Neuroscience Research, v. 1, n. 4, p. 267-282, 2001. 
COLLETTE, Fabienne et al. Exploring the unity and diversity of the neural substrates of executive functioning. Human brain mapping, v. 25 , n. 4, p. 409423, 2005.

COLLINS, Anne; KOECHLIN, Etienne. Reasoning, learning, and creativity: frontal lobe function and human decision-making. PLoS biology, v. 10, n. 3, p. e1001293, 2012.

COOLIDGE, Frederick L.; WYNN, Thomas. Executive functions of the frontal lobes and the evolutionary ascendancy of Homo sapiens. Cambridge archaeological journal, v. 11, n. 2, p. 255-260, 2001.

COWAN, Nelson et al. Age differences in visual working memory capacity: Not based on encoding limitations. Developmental science, v. 14, n. 5, p. 10661074, 2011.

DAMASIO, Antônio R. O erro de Descartes: emoção, razão e o cérebro humano. São Paulo: Companhia das Letras, 1996.

DIAMOND, Adele. The development and neural bases of memory functions as indexed by the $A B$ and delayed response tasks in human infants and infant monkeys. Annals of the New York Academy of Sciences, v. 608, n. 1, p. 267317, 1990.

DIAMOND, Adele. Normal development of prefrontal cortex from birth to young adulthood: Cognitive functions, anatomy, and biochemistry. Principles of frontal lobe function, p. 466-503, 2002.

DIAMOND, Adele. Executive functions. Annual review of psychology, v. 64, p. 135-168, 2013.

DIAMOND, Adele; GOLDMAN-RAKIC, Patricia S. Comparison of human infants and rhesus monkeys on Piaget's $A B$ task: Evidence for dependence on dorsolateral prefrontal cortex. Experimental brain research, v. 74, n. 1, p. 2440, 1989.

DIAMOND, Adele. AV/A Model System for Studying the Role of Dopamine in the Prefrontal Cortex during Early Development in Humans: Early and Continuously Treated Phenylketonuria. Handbook of developmental cognitive neuroscience, v. 433, 2001.

DIAMOND, Adele. The early development of executive functions. Lifespan cognition: Mechanisms of change, v. 210, p. 70-95, 2006.

DIAS, Natália Martins; MENEZES, Amanda; SEABRA, Alessandra Gotuzo. Alterações das funções executivas em crianças e adolescentes. Estudos interdisciplinares em Psicologia, v. 1, n. 1, p. 80-95, 2010.

ESPY, Kimberly Andrews; BULL, Rebecca. Inhibitory processes in young children and individual variation in short-term memory. Developmental neuropsychology, v. 28, n. 2, p. 669-688, 2005.

FERNALD, Lia $\mathrm{CH}$ et al. Examining early child development in low-income countries. Washington, D.C.: The World Bank, 2009. 
FERREIRA, F. O. et al. O exame neuropsicológico na idade pré-escolar. $\mathbf{N}$. Malloy-Diniz, LF, Fuentes, D., Mattos, P., Abreu (Ed.), Avaliação Neuropsicológica, p. 210-220, 2010.

FISCHER, Kurt W.; ROSE, Samuel P. Dynamic development of coordination of components in brain and behavior: A framework for theory and research. In: DAWSON, G.; FISHER, K. W. (org.) Human Behavior and the Developing Brain. New York: Guilford Pres, 1994, pp.3-66.

GARON, Nancy; BRYSON, Susan E.; SMITH, Isabel M. Executive function in preschoolers: a review using an integrative framework. Psychological bulletin, v. 134, n. 1 , p. $31,2008$.

GATHERCOLE, Susan E. et al. The structure of working memory from 4 to 15 years of age. Developmental psychology, v. 40, n. 2, p. 177, 2004.

GLASCOE, Frances Page. Screening for developmental and behavioral problems. Developmental Disabilities Research Reviews, v. 11, n. 3, p. 173179, 2005.

GOLDBERG, Elkhonon. The executive brain: Frontal lobes and the civilized mind. Oxford University Press, USA, 2002.

GOLDMAN-RAKIC, Patricia S. Circuitry of primate prefrontal cortex and regulation of behavior by representational memory. Comprehensive Physiology, 1987.

GRANTHAM-MCGREGOR, Sally et al. Developmental potential in the first 5 years for children in developing countries. The lancet, v. 369, n. 9555, p. 60-70, 2007.

HAZIN, Izabel et al. Contribuições da Neuropsicologia de Alexsandr Romanovich Luria para o debate contemporâneo sobre relações mente-cérebro. Mnemosine, v. 6, n. $1,2010$.

HONGWANISHKUL, Donaya et al. Assessment of hot and cool executive function in young children: Age-related changes and individual differences. Developmental neuropsychology, v. 28, n. 2, p. 617-644, 2005.

HUGHES, Claire; ENSOR, Rosie. Executive function and theory of mind in 2 year olds: A family affair?. Developmental neuropsychology, v. 28, n. 2, p. 645-668, 2005.

HUGHES, Claire; ENSOR, Rosie. Executive function and theory of mind: Predictive relations from ages 2 to 4 . Developmental psychology, v. 43, n. 6, p. 1447, 2007.

HUIZINGA, Mariëtte; DOLAN, Conor V.; VAN DER MOLEN, Maurits W. Agerelated change in executive function: Developmental trends and a latent variable analysis. Neuropsychologia, v. 44, n. 11, p. 2017-2036, 2006.

JOHNSON, Mark $\mathrm{H}$. The neural basis of cognitive development. In: DAMON, W. (org.) Handbook of child psychology: Vol. 2. Cognition, perception, and language. Hoboken, NJ, US: John Wiley \& Sons Inc. 1998, pp. 1-49. 
JOHNSON, Mark $\mathrm{H}$. et al. The emergence of the social brain network: Evidence from typical and atypical development. Development and psychopathology, v. 17, n. 3, p. 599-619, 2005.

JURADO, María Beatriz; ROSSELLI, Mónica. The elusive nature of executive functions: a review of our current understanding. Neuropsychology review, v. 17, n. 3, p. 213-233, 2007.

KOCHANSKA, Grazyna et al. Inhibitory control in young children and its role in emerging internalization. Child development, v. 67, n. 2, p. 490-507, 1996.

KOLB, Bryan; WHISHAW, Ian Q. Neurociência do comportamento. Manole, 2002.

KOTIK-FRIEDGUT, Bella. Development of the Lurian approach: A cultural neurolinguistic perspective. Neuropsychology Review, v. 16, n. 1, p. 43-52, 2006.

KRISTENSEN, Christian Haag; ALMEIDA, Rosa Maria Martins de; GOMES, William Barbosa. Desenvolvimento histórico e fundamentos metodológicos da neuropsicologia cognitiva. Psicologia: reflexão e crítica, v. 14, n. 2, p. 259-274, 2001.

KUHN, Deanna et al. Handbook of child psychology. Vol. 2, Cognition, perception, and language. Wiley, 1998.

LANDRY, Susan H.; SMITH, Karen E.; SWANK, Paul R. Environmental effects on language development in normal and high-risk child populations. In: Seminars in pediatric neurology. Elsevier, 2002. p. 192-200.

LEHTO, Juhani E. et al. Dimensions of executive functioning: Evidence from children. British Journal of Developmental Psychology, v. 21, n. 1, p. 59-80, 2003.

LENT, Roberto. Cem bilhões de neurônios: conceitos fundamentais de neurociência. São Paulo: Atheneu, 2001.

LEZAK, Muriel Deutsch et al. Neuropsychological assessment. Oxford University Press, USA, 2004.

LUNA, Beatriz. Developmental changes in cognitive control through adolescence. Advances in child development and behavior, v. 37, p. 233-278, 2009.

LURIA, Alexander R. O papel da linguagem na formação de conexões temporais e a regulação do comportamento em crianças normais e oligofrênicas. LURIA, AR Psicologia e Pedagogia: Bases Psicológicas da Aprendizagem e do desenvolvimento. São Paulo, Editora Moraes, p. 77, 1991.

MALLOY-DINIZ, L. F. et al. Exame das funções executivas. Avaliação Neuropsicológica. Porto Alegre: Artmed, p. 94-113, 2010.

MALLOY-DINIZ, Leandro F. et al. Neuropsicologia das funções executivas. Neuropsicologia: teoria e prática. Porto Alegre: Artmed, v. 187, 2008. 
MESULAM, M.-Marsel et al. The human frontal lobes: Transcending the default mode through contingent encoding. Principles of frontal lobe function, p. 8-30, 2002.

MILLER, Stephanie E.; MARCOVITCH, Stuart. Examining executive function in the second year of life: Coherence, stability, and relations to joint attention and language. Developmental Psychology, v. 51, n. 1, p. 101, 2015.

MISCHEL, Walter; SHODA, W; RODRIGUEZ, M.L. Delay of gratification in children. Science, 244, 933-938, 1989.

MISCHEL, Walter; UNDERWOOD, Bill. Instrumental ideation in delay of gratification. Child development, p. 1083-1088, 1974.

MIYAKE, Akira et al. The unity and diversity of executive functions and their contributions to complex "frontal lobe" tasks: A latent variable analysis. Cognitive psychology, v. 41, n. 1, p. 49-100, 2000.

MOFFITT, Terrie E. et al. A gradient of childhood self-control predicts health, wealth, and public safety. Proceedings of the National Academy of Sciences, v. 108, n. 7 , p. 2693-2698, 2011.

NAGAHAMA, Yasuhiro; FUKUYAMA, Hidenao; SHIBASAKI, Hiroshi. Dissociable mechanisms of attentional shifts within the human prefrontal cortex. In: International Congress Series. Elsevier, 2002. p. 137-145.

NELSON, Charles A.; THOMAS, Kathleen M.; DE HAAN, Michelle. Neuroscience of cognitive development: The role of experience and the developing brain. John Wiley \& Sons, 2012.

NELSON, J. M. et al. Executive Function in Preschool Age Children: Integrating Measurement, Neurodevelopment and Translational Research. book: McCardle P, Freund L, Griffin JA (ed.). Psychobiology of executive function in early development. Washington: Am Psychol Assoc, 2012.

PACKWOOD, Sonia; HODGETTS, Helen M.; TREMBLAY, Sebastien. A multiperspective approach to the conceptualization of executive functions. Journal of clinical and experimental neuropsychology, v. 33, n. 4, p. 456-470, 2011.

PAYNE, Kay T.; TAYLOR, Orlando L. Multicultural influences on human communication. Human communication disorders. An introduction, v. 6, 2002.

PELPHREY, Kevin A.; REZNICK, J. Steven. Working memory in infancy. Advances in child development and behavior, v. 31 , p. 173-231, 2003.

PENNINGTON, Bruce F. Dimensions of executive functions in normal and abnormal development. In N. A. Krasnegor, G. R. Lyon, \& P. S. Goldman-Rakic (org.), Development of the prefrontal cortex: Evolution, neurobiology, and behavior. Baltimore, MD, US: Paul H Brookes Publishing. 1997, pp. 265-281.

PIAGET, Jean. A educação artística e a psicologia da criança. Sobre a pedagogia, 1954. 
PINHEIRO, Marta. Fundamentos de neuropsicologia-o desenvolvimento cerebral da criança. Vita e Sanitas, v. 1, n. 1, p. 34-48, 2007.

REED, Marjorie A.; PIEN, Diana L.; ROTHBART, Mary K. Inhibitory self-control in preschool children. Merrill-Palmer Quarterly (1982-), p. 131-147, 1984.

REED, Umbertina Conti. Desenvolvimento normal do sistema nervoso central. Cap. 21. In: NITRINI, Ricardo; BACHESCHI, Luiz Alberto. A neurologia que todo médico deve saber. 2.ed. São Paulo: Atheneu, 2005. p.395-400.

RUSHWORTH, Matthew FS; PASSINGHAM, R. E.; NOBRE, A. C. Components of attentional set-switching. Experimental psychology, v. 52, n. 2, p. 83, 2005.

SHALLICE, T. Fractionation of the supervisory system. Principles of frontal lobe function, p. 261-277. New York: Oxford University Press, 2002.

SHALLICE, Tim. From neuropsychology to mental structure. Cambridge University Press, 1988.

SHONKOFF, Jack P.; MARSHALL, Paul C. The biology of developmental vulnerability. Handbook of early childhood intervention, v. 2, p. 35-53, 2000.

SMITH, Edward E.; JONIDES, John. Storage and executive processes in the frontal lobes. Science, v. 283, n. 5408, p. 1657-1661, 1999.

SNOW, Catherine E., \& VAN HEMEL, Susan B. (Eds.). Early childhood assessment: Why, what, and how. Washington, DC: National Academies Press, 2008.

STUSS, Donald T.; LEVINE, Brian. Adult clinical neuropsychology: lessons from studies of the frontal lobes. Annual review of psychology, v. 53, n. 1, p. 401433, 2002.

THATCHER, Robert W. Cyclic cortical reorganization: Origins of human cognitive development. 1994.

THEEUWES, Jan. Top-down and bottom-up control of visual selection. Acta psychologica, v. 135, n. 2, p. 77-99, 2010.

THOMPSON-SCHILL, Sharon L.; BEDNY, Marina; GOLDBERG, Robert F. The frontal lobes and the regulation of mental activity. Current opinion in neurobiology, v. 15, n. 2, p. 219-224, 2005.

TONIETTO, Lauren et al. Interfaces entre funções executivas, linguagem e intencionalidade. Paidéia, v. 21, n. 49, 2011.

VYGOTSKY, Lev Semenovitch. A formação social da mente. Trad. José Cipolla Neto, Luis Silveira Menna Barreto e Solange Castro Afeche. 1991.

ZELAZO, Philip D. et al. Hot and cool aspects of executive function: Relations in early development. Young children's cognitive development: Interrelationships among executive functioning, working memory, verbal ability, and theory of mind, p. 71-93, 2005. 